\title{
Recent Progress in Synthesis and Functionalization of Multimodal Fluorescent-Magnetic Nanoparticles for Biological Applications
}

\author{
Raquel Serrano García, Shelley Stafford ${ }^{(1)}$ and Yurii K. Gun'ko * (D) \\ School of Chemistry and Crann, University of Dublin, Trinity College, Dublin 2, Ireland; serranr@tcd.ie (R.S.G.); \\ sstaffo@tcd.ie (S.S.) \\ * Correspondence: igounko@tcd.ie; Tel.: +353-1-896-3543
}

Received: 17 December 2017; Accepted: 22 January 2018; Published: 25 January 2018

\begin{abstract}
There is a great interest in the development of new nanomaterials for multimodal imaging applications in biology and medicine. Multimodal fluorescent-magnetic based nanomaterials deserve particular attention as they can be used as diagnostic and drug delivery tools, which could facilitate the diagnosis and treatment of cancer and many other diseases. This review focuses on the recent developments of magnetic-fluorescent nanocomposites and their biomedical applications. The recent advances in synthetic strategies and approaches for the preparation of fluorescent-magnetic nanocomposites are presented. The main biomedical uses of multimodal fluorescent-magnetic nanomaterials, including biological imaging, cancer therapy and drug delivery, are discussed, and prospects of this field are outlined.
\end{abstract}

Keywords: nanoparticles; magnetic; multimodal; fluorescent; biomedical; imaging; diagnostic; therapy

\section{Introduction}

Magnetic nanomaterials have a range of unique properties and can offer new attractive options in many biomedical applications [1-9]. For example, magnetic nanoparticles can be selectively targeted to a specific biological entity of interest using an external magnetic field. Moreover, an alternating magnetic field can be used to provide selective heating of the area where magnetic particles are localized, and this serves as a basis for cancer hyperthermia therapy. Aqueous dispersions of superparamagnetic nanoparticles have also been used as contrast agents in magnetic resonance imaging (MRI).

The amalgamation of magnetic and other properties in one nanocomposite structure opens up a route to new types of nanomaterials with unique multimodal properties. For example, the combination of fluorescent and magnetic properties in one entity should result in unique fluorescent-magnetic nanocomposites, which could find a range of important biological applications including multimodal biological imaging, medical diagnostics and drug delivery systems. These nanocomposites could serve as multimodal assays for in vitro- and in vivo-bioimaging applications such as MRI and fluorescence microscopy. They could also be used as bimodal agents for cancer therapy, encompassing photodynamic and hyperthermic properties. Fluorescent-magnetic nanocomposites may also be utilised as a multimodal diagnostic and therapeutic tool, which could be used to identify, diagnose and simultaneously treat various diseases. Other exciting applications of these nanocomposites include cell tracking, cytometry and magnetic separation, which could be easily controlled and monitored using fluorescent or confocal microscopy and MRI [10-12]. Thus, fluorescent-magnetic nanostructures are fascinating materials that have attracted a lot of attention and been the subject of several interesting reviews $[2,7,9,10,12-16]$. Our review will focus only on recent developments of magnetic-fluorescent nanocomposites and their selected biological applications. 


\section{Preparation of Magnetic-Fluorescent Nanocomposites}

Despite many problems related to the development of multimodal magnetic-fluorescent nanoparticles, important advances have been achieved in this field. The main challenge in the synthesis of magnetic-fluorescent nanoparticles is quenching of the luminescence of the fluorophore when it is in direct contact with the magnetic particle. This problem is related to the energy and electron transfer processes between the fluorophore species and the magnetic nanoparticles $[12,17,18]$. Therefore, during recent years, many groups have tried to overcome the problem of quenching and develop new improved multimodal nanomaterials for biomedical applications.

\subsection{Fluorescent Silica Coated Magnetic Nanoparticles}

Different strategies have been followed to produce a reliable fluorescent nanostructure. One of the most used and most straightforward approaches to avoid the quenching to the fluorescent entity is to coat the magnetic core with a layer of $\mathrm{SiO}_{2}$.

Through careful control of the thickness of the silica shell, the quenching of the fluorophore by the magnetic core may be prevented. Furthermore, silica can be easily functionalized, facilitating the bonding of fluorescent molecules to the surface.

Many different strategies following this approach have been reported in the last years. Silica coated nanoparticles have been functionalized using different organic dyes. Chekina et al. [19] reported the preparation of FITC-labelled $\gamma-\mathrm{Fe}_{2} \mathrm{O}_{3}-\mathrm{SiO}_{2}$-AP nanoparticles. FITC (Fluorescein 5-isothiocyanate) is a fluorescent dye that is $\mathrm{pH}$ dependent. For this dye, the fluorescence is stronger at $\mathrm{pH}$ between 5 and 8, allowing the use of FITC functionalised nanoparticles as $\mathrm{pH}$-sensing fluorescent probes in imaging (Figure 1).

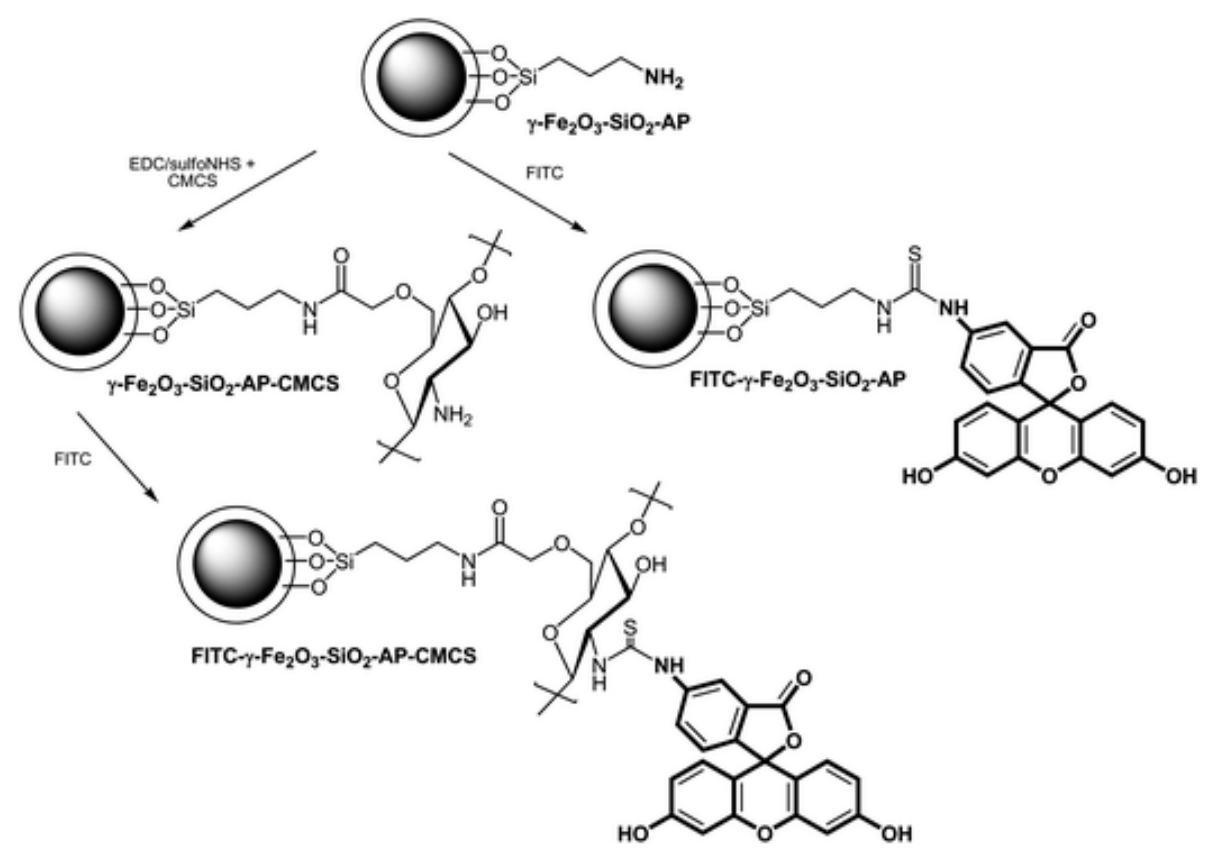

Figure 1. Labelling of $\gamma-\mathrm{Fe}_{2} \mathrm{O}_{3}-\mathrm{SiO}_{2}-\mathrm{AP}$ and $\gamma-\mathrm{Fe}_{2} \mathrm{O}_{3}-\mathrm{SiO}_{2}-\mathrm{AP}-\mathrm{CMCS}$ nanoparticles with FITC. Adapted from ref. [19].

Another strategy to develop fluorescent magnetic nanostructures is to incorporate the fluorescent entity directly into the silica shell. The production of monodisperse and size-controllable core-shell nanoparticles in which FITC was incorporated in the nonporous silica shell has been reported a number of times [20-22]. The silica coated magnetic nanoparticles with organic dyes such as FITC can be further modified with folic acid and $\mathrm{pH}$-sensitive polymers such as poly(2-hydroxyethyl 
methacrylate) (P(HEMA)) [23], poly(acrylic acid) (PAA) [24] or amino acids such as L-lysine ad L-arginine [25]. Rhodamine B isothiocyanate (RITC) has also been used as fluorescent organic dye in the synthesis of fluorescent silica coated magnetic nanoparticles. For example, Cho et al. reported the incorporation of magnetic iron nanoparticles and the organic dye into a silica coating of nanoparticles with further conjugation with Cetuximab for targeting and imaging cancer cells [26]. In another study, squatyliumindocyanine $\left(\mathrm{Cy} 5-\mathrm{NH}_{2}\right)$ was used as a dye to functionalise $\mathrm{Fe}_{3} \mathrm{O}_{4} @ \mathrm{SiO}_{2}$ nanoparticles with an outer shell of carboxymethyl chitosan (CMCS) [27].

The incorporation of fluorescent QDs to the silica shell in silica coated magnetic nanostructures has also been investigated and reported. QDs have unique optical properites and this makes them an interesting material for bioimaging or biolabelling. However, the potential leakage of heavy metals is a serious drawback for their use in biomedical applications. Coating QDs in a biocompatible material such as silica has arisen as an option to prevent the leaking. For example, CdSeS QDs were used in the synthesis of multifunctional fluorescent hollow silica coated magnetic nanoparticles in which both materials were trapped in a silica shell. Folic acid was conjugated to silica nanocomposites to be used for tumour cell imaging [28]. Xu et al. prepared $\mathrm{Fe}_{3} \mathrm{O}_{4} @ \mathrm{SiO}_{2}-\mathrm{SH}$ nanoparticles via the hydrolysis of a sol-gel precursor. In the last synthetic step, $\mathrm{Fe}_{3} \mathrm{O}_{4} @ \mathrm{SiO}_{2}-\mathrm{SH}$ were combined with a water soluble CdSe/ZnS QDs solution, resulting in the final fluorescent material [17]. Magnetic-encoded fluorescent $\mathrm{CdTe} / \mathrm{Fe}_{3} \mathrm{O}_{4} @ \mathrm{SiO}_{2}$ nanospheres were synthesized following a reverse microemulsion method (Figure 2) [29]. The same method was used by Gao et al. in the development $\mathrm{CdTe}-\mathrm{Fe}_{3} \mathrm{O}_{4} @ \mathrm{SiO}_{2}$ microspheres which were covalently bonded to graphene oxide [30]. The reverse microemulsion method was also chosen for the preparation of fluorescent magnetic nanoparticles consisting of silica wrapped $\mathrm{CdTe}$ and $\mathrm{Fe}_{3} \mathrm{O}_{4}$ nanoparticles conjugated with anti-BRCAA1 antibody. ZnS QDs were chosen for the synthesis of superparamagnetic $\mathrm{ZnS@} \mathrm{Fe}_{3} \mathrm{O}_{4}$ nanospheres [31]. MPS (3-mercaptopropyltrimethoxysilane) capped $\mathrm{ZnS}$ QDs and $\mathrm{Fe}_{3} \mathrm{O}_{4} @ \mathrm{SiO}_{2}$ nanoparticles were bound through Si-O groups between the MPS and Si-O groups of the $\mathrm{Fe}_{3} \mathrm{O}_{4}$ nanoparticles surface [32]. Yin et al. synthesised $\mathrm{Fe}_{3} \mathrm{O}_{4} @ \mathrm{SiO}_{2}$ nanoparticles and modified the surface using APS (3-aminopropyltrimethoxysilane). CdTe QDs were bound by electrostatic interactions to the silica coated magnetic nanoparticles [33,34].

Other alternative approaches to prepare fluorescent magnetic nanoparticles with the presence of a silica shell can be through the use of $\mathrm{Cr}_{2} \mathrm{O}_{3}$-doped $\mathrm{CoFe}_{2} \mathrm{O}_{4}$ nanoparticles coated with a monolayer of $\mathrm{SiO}_{2}$. Ferromagnetic $\mathrm{CoFe}_{2} \mathrm{O}_{4}$ biased by an antiferromagnetic $\left(\mathrm{Cr}_{2} \mathrm{O}_{3}\right)$ systems are studied in light of magnetoresistive applications [35].

Silica coating has also been used in the development of other fluorescent magnetic nanostructures such as in the synthesis of luminescent magnetic mesoporous carbon nanospheres in which $\mathrm{CoFe}_{2} \mathrm{O}_{4}$ is the magnetic component and resorcinol-formaldehyde polymer acts as the luminescent component [36]. 

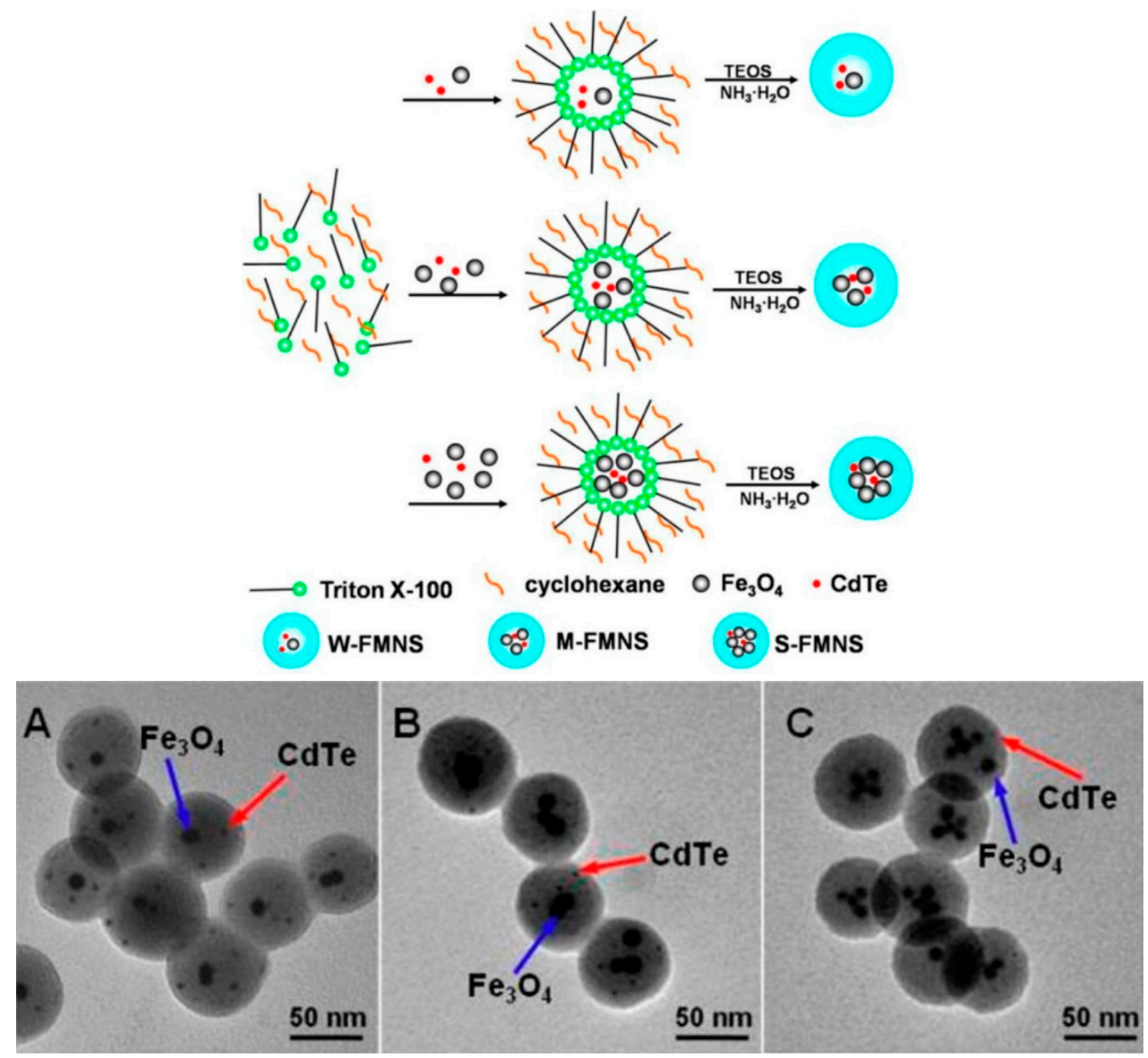

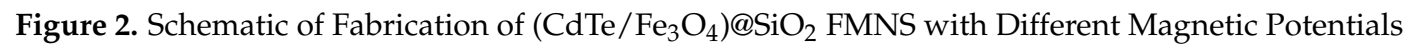
and TEM images of $\left(\mathrm{CdTe} / \mathrm{Fe}_{3} \mathrm{O}_{4}\right) @ \mathrm{SiO}_{2}$ FMNS: (A) W-FMNS, (B) M-FMNS, and (C) S-FMNS. Adapted from ref. [29].

\subsection{Fluorescent Polymer Coated Magnetic Nanoparticles}

\subsubsection{Silica-Polymer Magnetic-Fluorescent Nanocomposites}

Conjugated polymers are a very promising class of functional materials in the production of fluorescent nanoparticles. These polymers can be conveniently incorporated onto silica coated magnetic nanoparticles by the layer-by-layer self-assembly (LbL) technique. For example, using this technique, the cationic conjugated polymer PFV was chosen as a luminescent polymer to be incorporated onto the $\mathrm{CoFe}_{2} \mathrm{O}_{4} @ \mathrm{SiO}_{2}$ core-shell nanoparticles [37]. Pfaff et al. also synthesised fluorescent and magnetic core-shell nanospheres by grafting a glycol-copolymer consisting of 6-O-methacryloylgalactopyranose (MAGal) and 4-(pyrenyl)butyl methacrylate (PyMA) onto silica encapsulated iron oxide particles (Figure 3) [38]. 

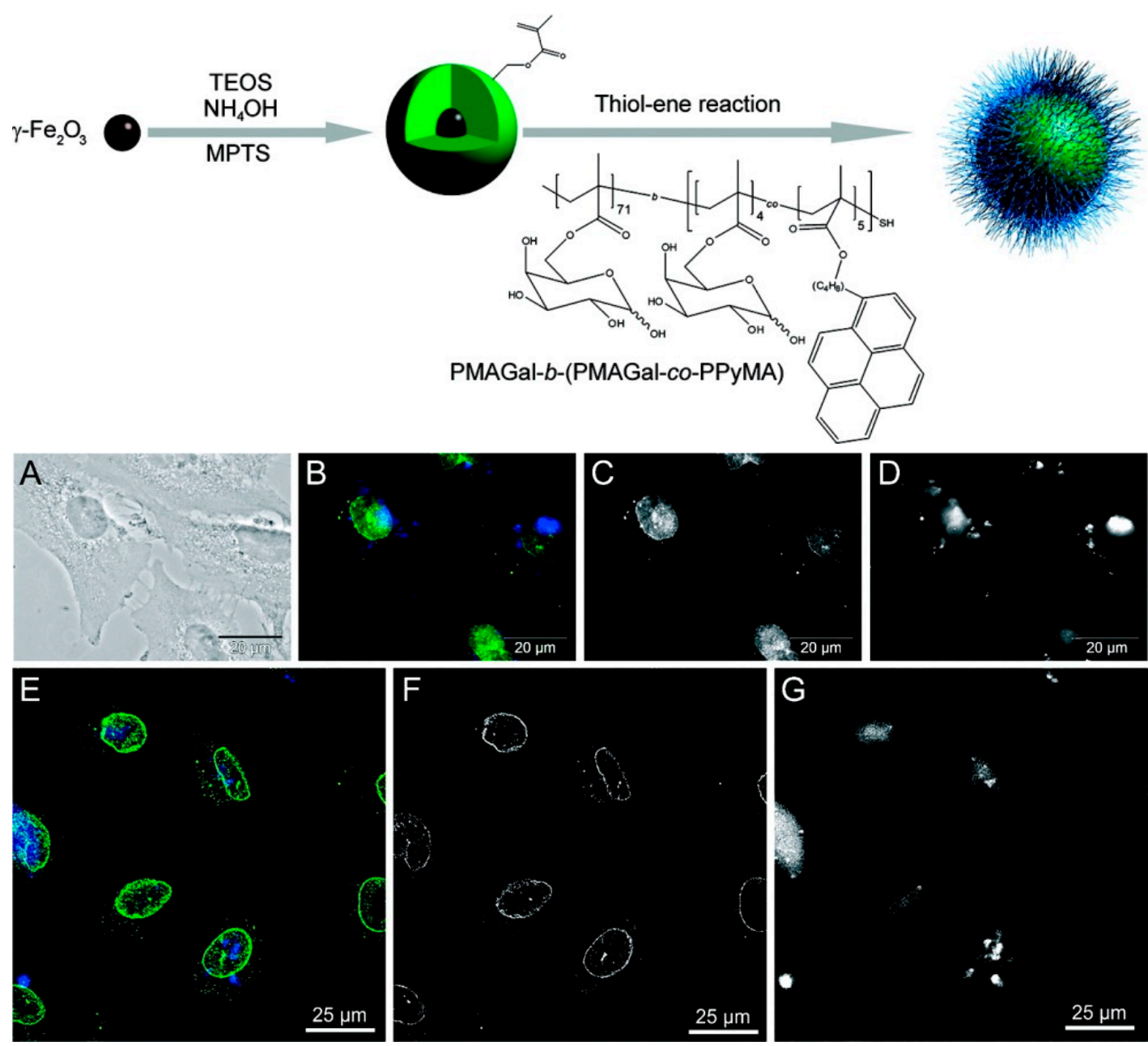

Figure 3. Synthesis of Fluorescent, Magnetic, Glycopolymer-Grafted Nanoparticles and Microscope images of A549 cells exposed to glycopolymer-grafted nanoparticles. (A-D) epifluorescence microscopy, (E-G) confocal microscopy. (A) Transmission image, (B,E) merged fluorescence images, (C,F) fluorescence images that exclusively show the green light emitting structures in the cell (nuclear membrane), and $(\mathbf{D}, \mathbf{G})$ fluorescence images that exclusively show the blue light emitting structures (pyrene in the glycocopolymer covered nanospheres). Adapted from ref. [38].

In another study, $\mathrm{Fe}_{3} \mathrm{O}_{4} @ \mathrm{mSiO}_{2}$ nanoparticles were prepared by grafting fluorescent polymethacrylic acid and folic acid onto the silica coated magnetic material [39]. Polyethyleneimine (PEI) modified yolk-shell nanocapsules were also produced from PEI coated fluorescent mesoporous $\mathrm{SiO}_{2}$ shells and $\mathrm{Fe}_{3} \mathrm{O}_{4}$ cores [40].

Carboxyl-funtionalized superparamagnetic $\mathrm{Fe}_{3} \mathrm{O}_{4}$ nanoparticles and individual amino-funtionalised silica coated fluorescent $\mathrm{NaYF}_{4}: \mathrm{Yb}$, Er up-conversion nanoparticles were synthesized, resulting in magnetic luminescent multifunctional nanoparticles (Figure 4) [41]. Gai et al. prepared a monodisperse core-shell-structured $\mathrm{Fe}_{3} \mathrm{O}_{4} @ \mathrm{nSiO}_{2} @ \mathrm{mSiO}_{2} @ \mathrm{NaYF}: \mathrm{Yb}^{3+}, \mathrm{Er}^{3+} / \mathrm{Tm}^{3+}$ nanocomposites with mesoporous, up-conversion luminescent and magnetic properties [42]. 


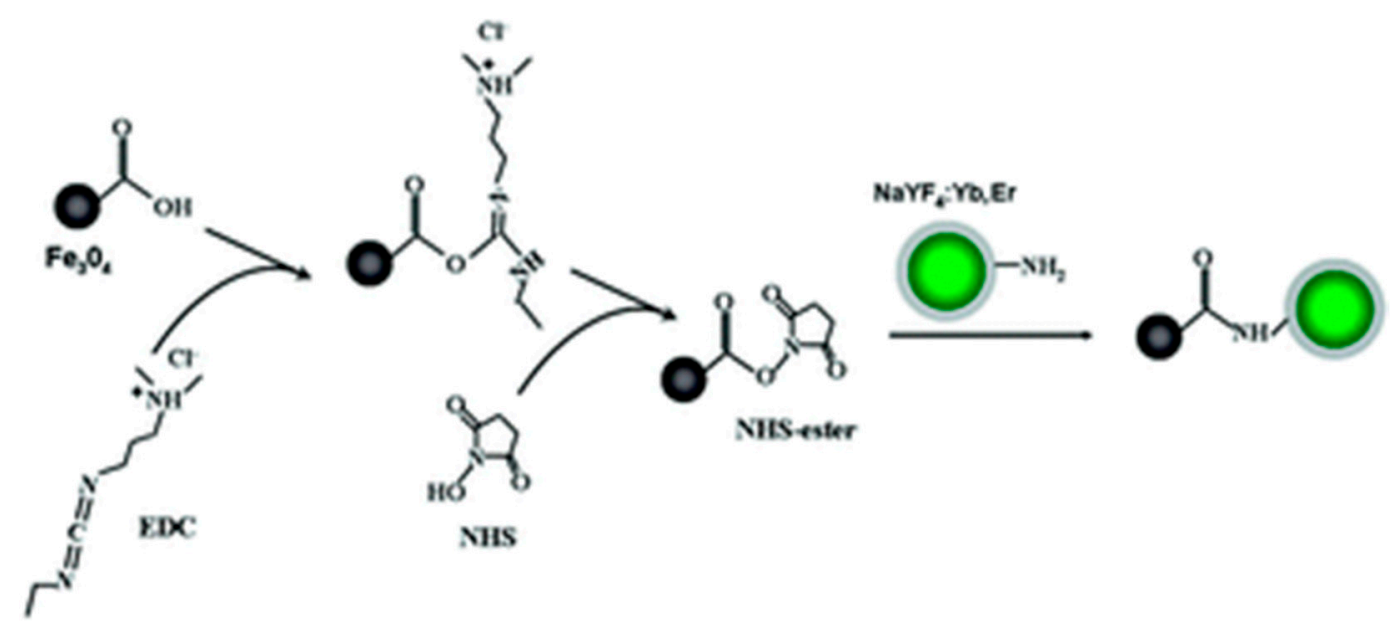

Figure 4. Schematic illustration of the formation of $\mathrm{Fe}_{3} \mathrm{O}_{4} / \mathrm{NaYF}_{4}$ nanocomposites through EDC/NHS coupling chemistry. Adapted from ref. [41].

\subsubsection{Polymer and Organic Dye Magnetic-Fluorescent Nanocomposites}

A different approach in the development of fluorescent and magnetic nanocomposites is the incorporation of polymer to the nanostructure. A magnetic core can be encapsulated or embedded into a polymer matrix which can be functionalized with different luminescent entities. For example, Lim et al. synthesized amphiphilic pyrenyl polyethylene glycol (PEG) by the conjugation of hydrophilic PEG with hydrophobic and fluorescent 1-pyrenebutyric acid through an esterification process resulting in a high UV fluorescent intensity in aqueous phase. The polymer was incorporated into $\mathrm{MnFe}_{2} \mathrm{O}_{4}$ magnetic nanoparticles (NPs) [18]. In another study, iron-platinum nanoparticles were embedded in a poly(methacrylic acid) (PMA) polymer shell and fluorescently labelled with the dye ATTO 590 [43]. Hydrophobic up-conversion nanoparticles (UCNPs) together with iron oxide nanoparticles (IONPs) were encapsulated by using an amphiphilic block copolymer, poly (styrene-block-allyl alcohol) (PS16-b-PAA10), via a microemulsion method, obtaining an UC-IO@Polymer multi-functional nanocomposite system. Fluorescent dye and anti-cancer drug molecules can be further loaded inside the UC-IO@Polymernanocomposite for additional modalities [44]. Magnetic-fluorescent semiconductor polymer nanospheres (MF-SPNs) have been synthesized by encapsulation of hydrophobic conjugated polymers and iron oxide nanoparticles in phospholipid micelles. Following the same synthesis, four different fluorescent conjugated polymers were used, yielding aqueous dispersions of nanoparticles which emit across the visible spectrum [45]. Novel water-soluble dendritic-linear-brush-like triblock copolymer polyamidoamine-b-poly(2-(dimethylamino)ethyl methacrylate)-b-poly(poly(ethylene glycol) methyl ether methacrylate) (PAMAM-b-PDMAEMA-b-PPEGMA)-grafted superparamagnetic iron oxide nanoparticles (SPIONs) were successfully prepared via a two-step copper-mediated atom transfer radical polymerization (ATRP) method by He et al. (Figure 5) [46]. Polymer-coated magnetic particles (MPs) were also prepared to study the binding of fluorescent dye (3-(dansylamino)phenylboronic acid) on the surface and its $\mathrm{H}_{2} \mathrm{O}_{2}$-induced release. For this goal, multilayer films were produced by LbL deposition of shikimic acid-appended poly(allylamine hydrochloride) (SA-PAH) and poly(styrenesulfonate) (PSS) on the surface of MPs [47]. Dual-modal fluorescent-magnetic nanoparticles with surface folic acid have also been produced by co-encapsulation of a far-red/near-infrared (FR/NIR)-emissive conjugated polymer (Poly[9,9-bis(6'-(N,N-dimethylamino)hexyl)fluorenyldivinylene-alt-4,7-(2,1,3,-benzothiadiazole)]) (PFVBT) and lipid-coated iron oxides (IOs) into a mixture of poly(lactic-co-glycolic-acid)-poly(ethylene glycol)-folate (PLGA-PEG-FOL) and PLGA [48]. Similarly, $\mathrm{Fe}_{3} \mathrm{O}_{4}$ nanoparticles coated with biodegradable poly (DL-lactic acid-co- $\alpha, \beta$-malic acid) copolymer were covalently bound to FITC [49]. 
Wang et al. reported the preparation of (PEG)ylated polymeric lipid vesicles containing iron oxide nanoparticles and the anticancer drug doxorubicin (DOX) [50].

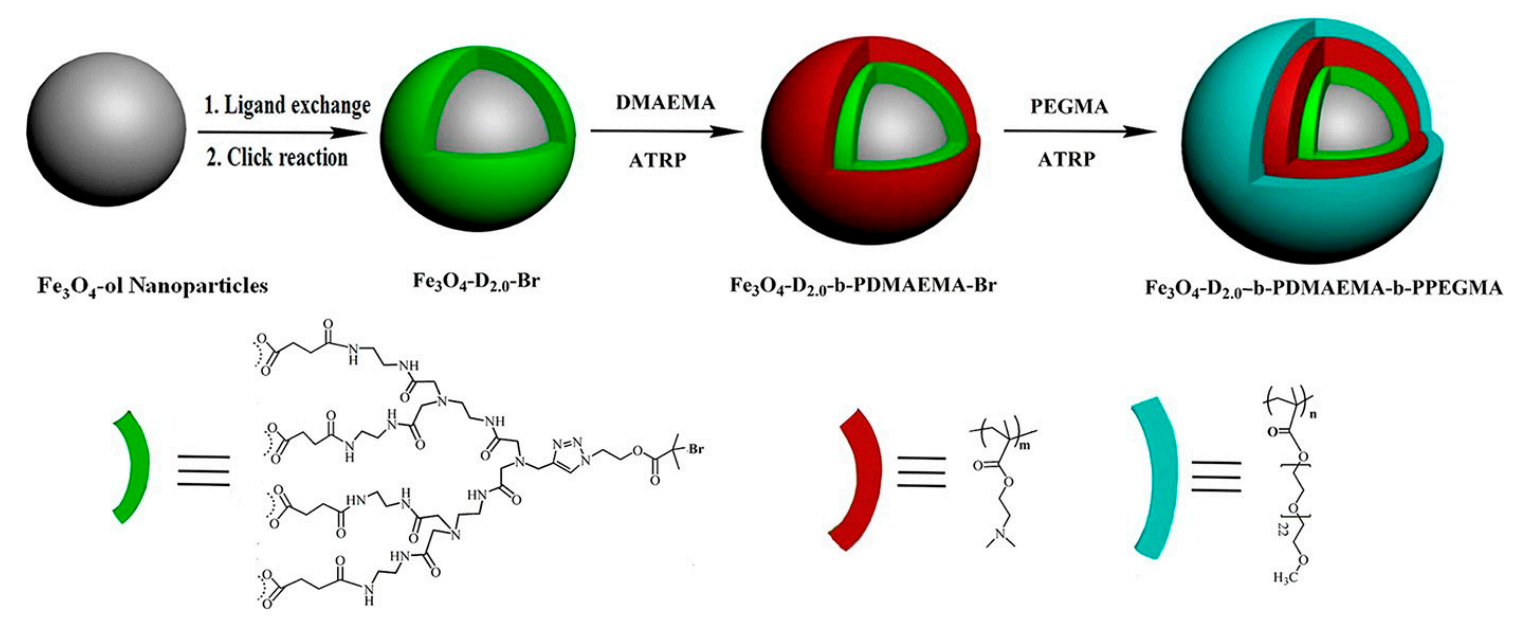

Figure 5. Surface Modification Process of Superparamagnetic $\mathrm{Fe}_{3} \mathrm{O}_{4}$ Nanoparticles. Adapted from ref. [46].

In another study, $\mathrm{Fe}_{3} \mathrm{O}_{4} /$ poly(St-co-GMA) nanoparticles were first synthesized as seed particles. $\mathrm{Eu}(\mathrm{AA}) 3 \mathrm{Phen}$ was then copolymerized with the remaining styrene and GMA (glycidyl methacrylate) to form the fluorescent polymer shell in the second step. Red luminescence from the FMCNPs is confirmed by the salient fluorescence emission peaks of europium ions at 594 and $619 \mathrm{~nm}$ as well as 2-photon confocal scanning laser microscopy [51]. The amphiphilic fluorescent poly(HFMA-co-VBK)-g-PEG copolymers were prepared by polymerization of the hydrophobic HFMA $(2,2,3,4,4,4$-Hexafluorobutyl methacrylate) monomers, hydrophilic PEGMA macromonomers, and fluorescent monomers VBK (9-(4-vinylbenzyl)-9H-carbazole) in THF [52]. Iron oxide nanoparticles (SPION) were used as the core, along with cyanine fluorescent dye emitting in the far-red region, a polyethylene glycol (PEG5000) coating, and the membranotropic peptide gH625 (from the cell-penetrating peptides (CPP) family) were all used in the preparation of this fluorescent nanosystem [53]. DOX and four different molecular building blocks act through a multivalent molecular recognition between adamantine (Ad) and $\beta$-cyclodextrin (CD) motifs. The four different building blocks used in the synthesis are Ad-grafted polyamidoaminedendrimers (Ad-PAMAM), b-CD-grafted branched polyethylenimine (CD-PEI), Ad-functionalized polyethylene glycol (Ad-PEG), and $6 \mathrm{~nm}$ Ad-grafted $\mathrm{Zn}_{0.4} \mathrm{Fe}_{2.6} \mathrm{O}_{4}$ superparamagnetic nanoparticles. This self-assembled synthetic strategy enables control over size, surface chemistry and loading of the nanoparticles for different applications [54].

\subsubsection{Polymer and QDs-Magnetic-Fluorescent Nanocomposites}

A range of fluorescent-magnetic nanocomposites have also been prepared by using different sized quantum dots and varying amounts of $\gamma-\mathrm{Fe}_{2} \mathrm{O}_{3}$ magnetic nanoparticles into poly(styrene/acrylamide) copolymer nanospheres. The fabrication of the multifunctional nanospheres involved the incorporation of the quantum dots and $\gamma-\mathrm{Fe}_{2} \mathrm{O}_{3}$ nanoparticles into the copolymer [55]. The encapsulation of both magnetic and infrared emitting nanoparticles into a polymeric matrix leads to a magnetic-fluorescent hybrid nanostructure with multimodal magnetic-fluorescent imaging abilities (Figure 6). The nanostructures were prepared by combining nontoxic iron superparamagnetic nanoparticles with $\mathrm{PbS}$ quantum dots through encapsulation with the biocompatible polymer poly(lactic-co-glycolic-acid) [56]. Hydrophobic trioctylphosphine oxide (TOPO)-capped CdSe@ZnS quantum dots (QDs) were assembled on polyethyleneimine (PEI)-coated $\mathrm{Fe}_{3} \mathrm{O}_{4}$ nanoparticles [57]. 

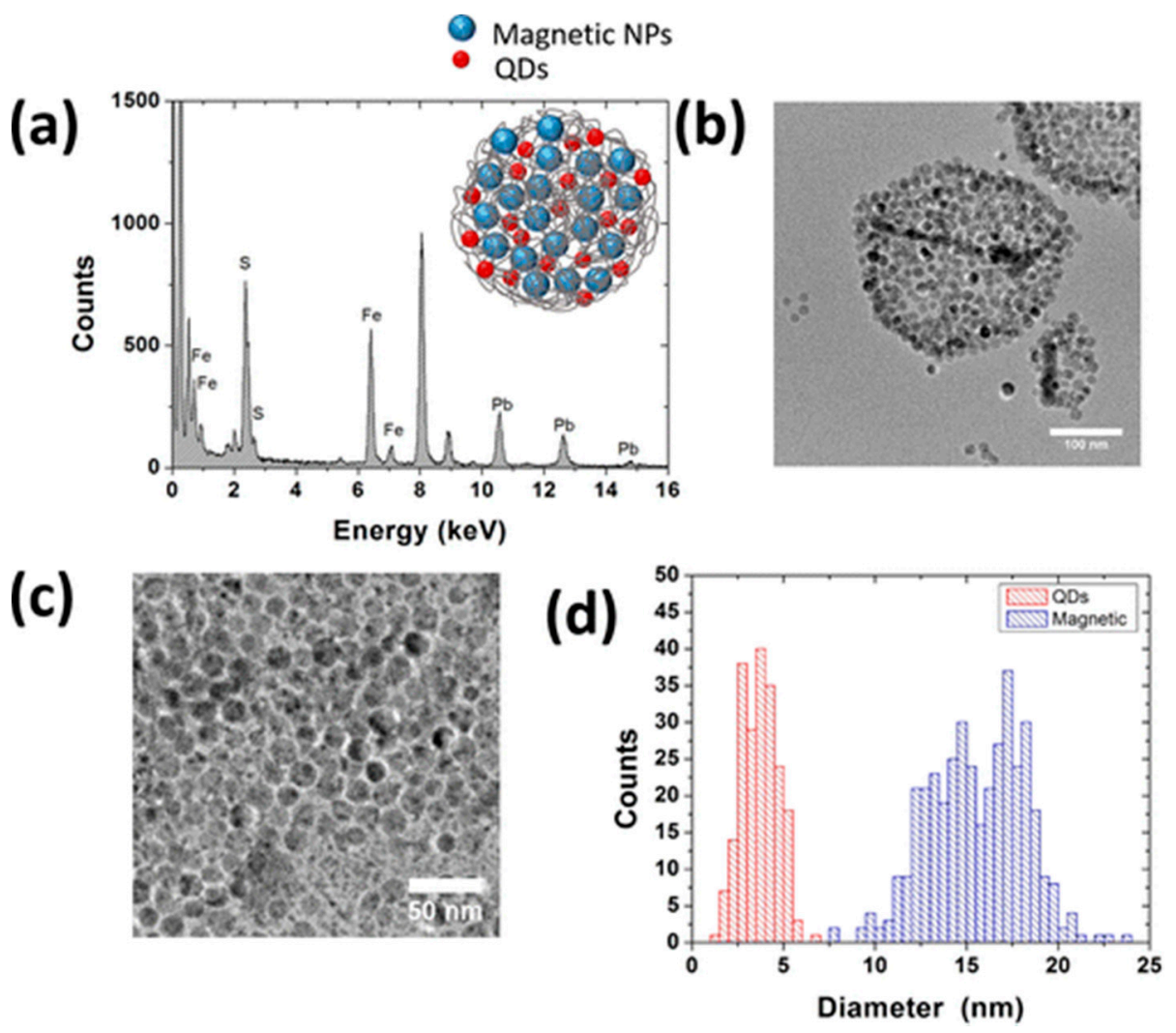

(e)

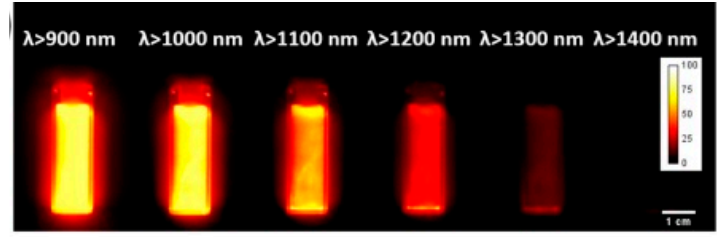

(g)

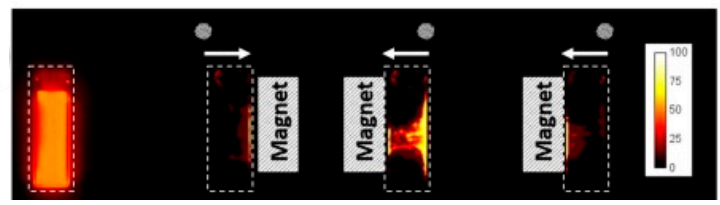

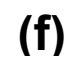

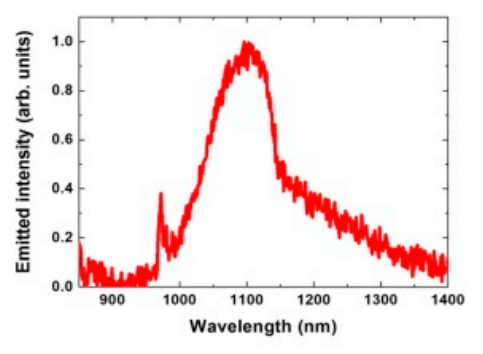

Figure 6. Top: Characterization of luminescent-magnetic HNS. (a) Compositional analysis (EDX) of a PLGA nanostructure denoting the presence of elements of both magnetic NPs and QDs. (inset) Schematic diagram of the magnetic NPs and QDs in the PLGA nanostructure; (b) TEM image of a typical PLGA nanostructure synthesized in this work; (c) A detailed TEM image of a PLGA nanostructure revealing the presence of two types of NPs inside the structure; (d) Size distribution of both types of particles obtained from TEM images. The size distribution corresponds to the sizes of the magnetic NPs and QDs (right). Fluorescence analysis; (e) Infrared fluorescence images of a PBS solution containing the HNS, as obtained under $808 \mathrm{~nm}$ laser excitation and by employing different long pass filters; (f) Emission spectrum of HNS; (g) IR fluorescence images of the same dispersion in the presence of a magnet, demonstrating the potential for the magnetic control of the nanostructures while enabling visual tracking through the IR luminescence. Adapted from [56].

In another study, superparamagnetic $\mathrm{Fe}_{3} \mathrm{O}_{4} \mathrm{NPs}$ and visible light emitting fluorescent $\mathrm{CdTe} / \mathrm{CdS}$ quantum dots were conjugated using the covalent linking of the oxidized dextran shell of magnetic particles to the glutathione ligands of QDs [58]. Hydrophobic trioctylphosphine oxide-capped $\mathrm{CdSe} / \mathrm{ZnS}$ quantum dots (QDs) and oleic acid-capped nano- $\gamma-\mathrm{Fe}_{2} \mathrm{O}_{3}$ magnetic particles are directly, selectively and controllably assembled on branched poly(ethylene imine)-coated nanospheres without 
any pre-treatment. This is crucial in keeping the high quantum yield of QDs and the good dispersibility of $\gamma-\mathrm{Fe}_{2} \mathrm{O}_{3}$ [59]. Magnetic core/shell $\mathrm{Fe}_{3} \mathrm{O}_{4} / \mathrm{ZnSe}$ NPs with a spherical shape were prepared by an organometallic synthesis. The $7 \mathrm{~nm}$ core $/ 3 \mathrm{~nm}$ shell NPs show good magnetic and photoluminescence (PL) responses [60]. Ruan et al. prepared nanocontainers composed by polymeric micelles with hydrophobic core into which quantum dots or rods and superparamagnetic iron oxide nanoparticles were encapsulated [61]. QDs with emissions in the near-infrared range $(\sim 800 \mathrm{~nm})$ are conjugated onto the surface of a nanocomposite consisting of a spherical polystyrene matrix $(\sim 150 \mathrm{~nm})$ and the internally embedded, high fraction of superparamagnetic $\mathrm{Fe}_{3} \mathrm{O}_{4}$ nanoparticles $(\sim 10 \mathrm{~nm})$. For drug storage, the chemotherapeutic agent paclitaxel (PTX) is loaded onto the surfaces of these composite multifunctional nanocarriers by using a layer of biodegradable poly(lactic-co-glycolic acid) (PLGA), see Figure 7 [62]. Superparamagnetic iron oxide nanoparticles (SPIO) and near-infrared fluorescent CdTe quantum dots (QDs) were covalently coupled onto the surface of CNTs in sequence via LBL assembly (Figure 8) [63]. Chitosan (CS) coated magnetic-fluorescent nanoparticles (CS- $\mathrm{Fe}_{3} \mathrm{O}_{4} @ \mathrm{ZnS}: \mathrm{Mn}$ ) were synthesized in aqueous media under ambient pressure [64]. Chitosan encapsulated iron oxide, CdS QDs and podophyllotoxin were synthesised by Walia et al. [65]. $\mathrm{Fe}_{3} \mathrm{O}_{4}$ magnetic NPs acts as the magnetic targeting carrier and $\mathrm{Gd}$ (aspirin) $)_{3} \cdot 2 \mathrm{H}_{2} \mathrm{O}$ as the fluorescent-labelled drug. These two components were incorporated into chitosan microspheres to prepare magnetic and fluorescent chitosan microspheres as a drug delivery system [66].

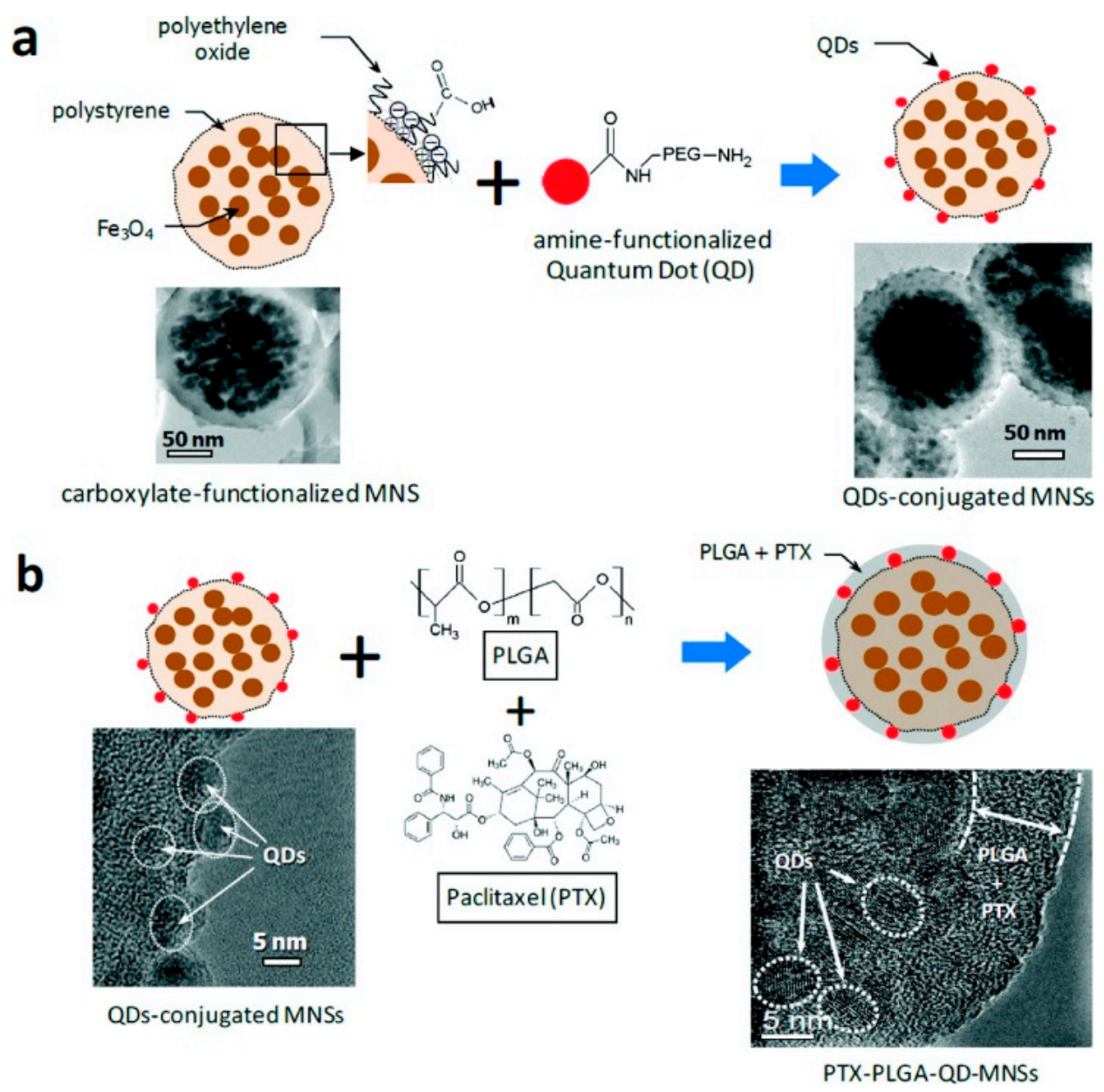

Figure 7. Schematic diagrams illustrating surface functionalization of MNSs: (a) Conjugation of amine-functionalized quantum dots (QDs) to the surface of carboxylate-functionalized MNSs using conventional NHS/EDC coupling method; (b) PTX loading using a thin PLGA coat on the surface of QD-MNSs. Adapted from ref. [62]. 

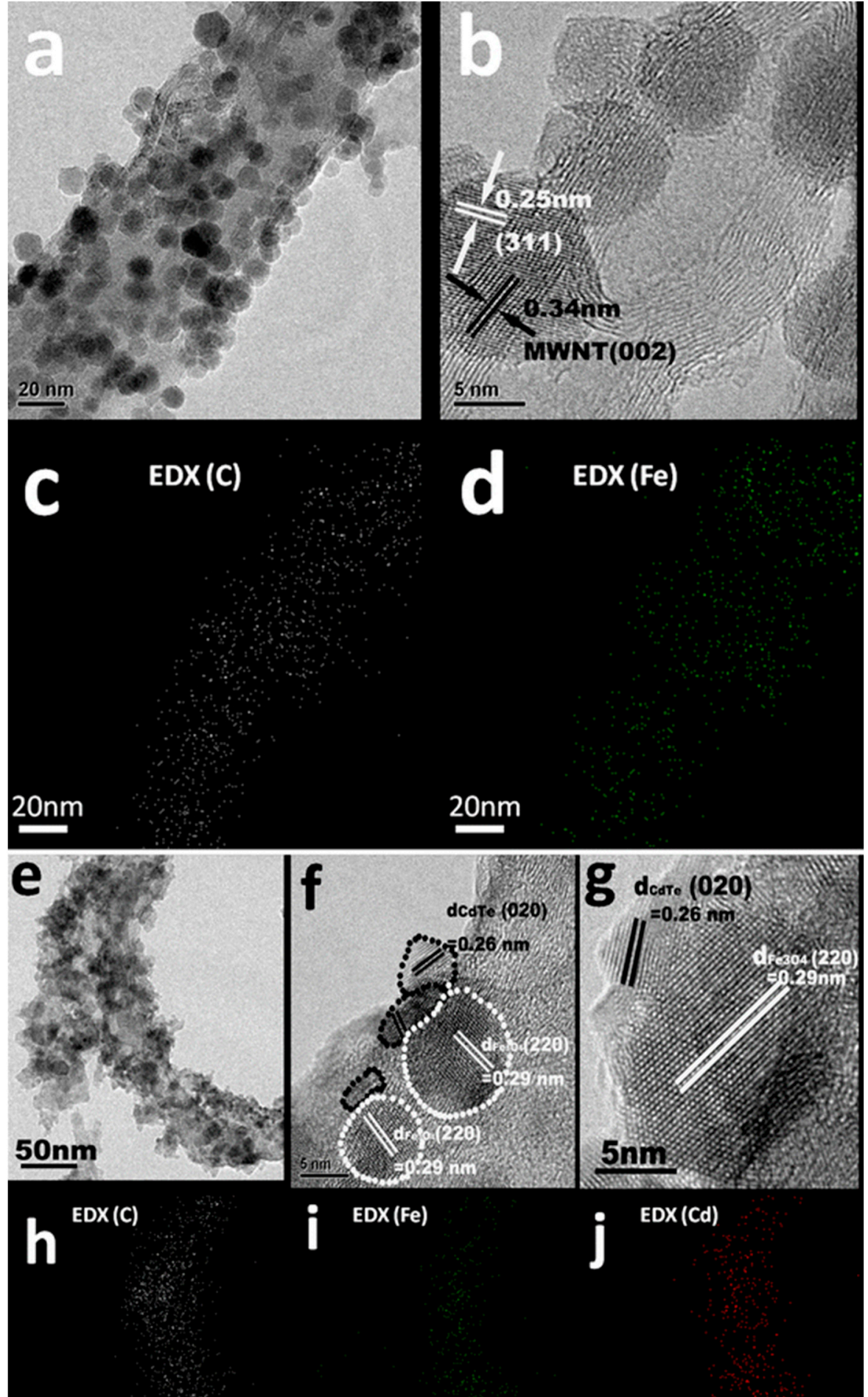

$50 \mathrm{~nm}$

$50 \mathrm{~nm}$

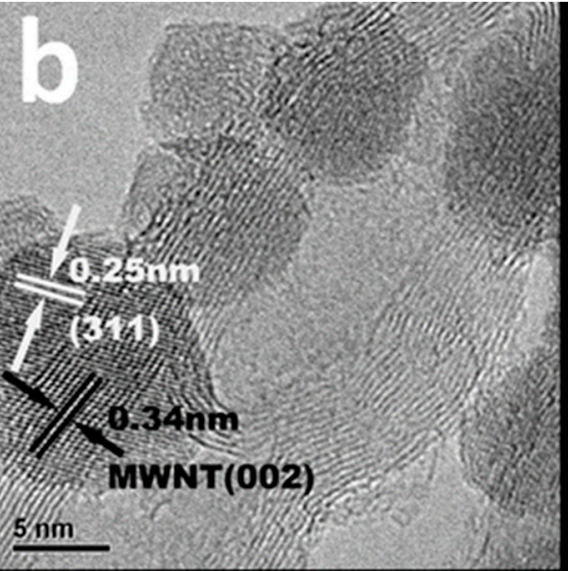

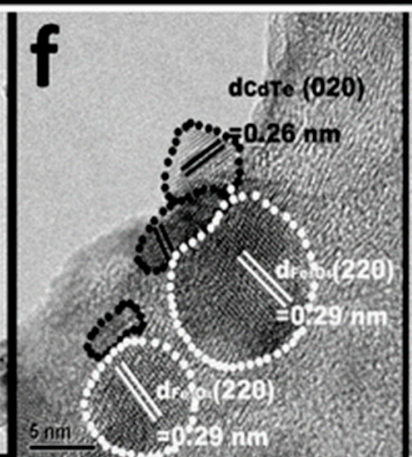

EDX (Fe)

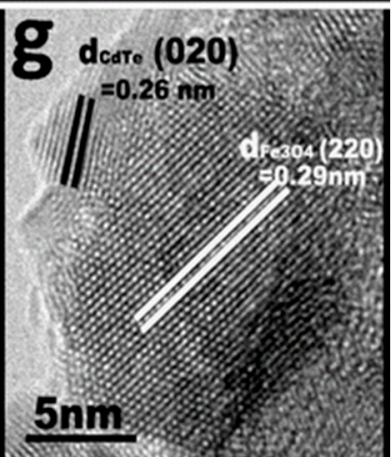

EDX (Cd)

Figure 8. Morphological and structural characterizations of CNT-SPIO (a-d) and CNT-SPIO-CdTe nanohybrids $(\mathbf{e}-\mathbf{j})$ prepared by LBLassembly in combination with covalent connection technique: (a) bright field TEM image of CNT-SPIO; (b) HRTEM image of CNT-SPIO; (c,d) EDX elemental mapping of $\mathrm{C}$ and Fe with a specific CNT-SPIO nanohybrid respectively; (e) bright field TEM image of CNT-SPIO-CdTe; $(\mathbf{f}, \mathbf{g})$ HRTEM images of CNT-SPIO-CdTe; $(\mathbf{h}-\mathbf{j})$ EDX elemental mapping of C, Fe and $\mathrm{Cd}$ with a specific CNT-SPIO-CdTenanohybrid respectively. Adapted from ref. [63]. 
The synthesis of a hydrophilic colloidal bimodal nanoprobe (FePt-CdS) was carried out through a seed-mediated nucleation and growth technique. In this synthesis of the complex nanostructure, glutathione (GSH) was used as the capping agent to render biocompatibility and dispersibility [67]. A chitosan-based drug delivery system, composed of $\mathrm{Fe}_{3} \mathrm{O}_{4}$ magnetic NPs, CdTe@ZnS QDs and the anti-cancer drug DOX, was designed and fabricated by Ding et al. [68].

A polymer solution of high molecular weight polystyrene, superparamagnetic magnetite NPs and coumarin-153 dye were used to prepare nanowires in the range of $200 \mathrm{~nm}$ in length. The material was prepared by a facile route using vacuum infiltration in porous alumina membranes. The resultant nanowires were functionalised with Inmonoglobulin-G and AntiCD54 antibodies to confer dual imaging and immunoresponse modality [69]. Rhodamine-coated cobalt ferrite magnetic fluorescent (MF) nanoparticles linked to a quenching molecular system containing a miR124a binding sequence (MF-miR124a beacon) were synthesized xdzsaw [70]. Superparamagnetic nanoparticles (20-40 nm) of maghemite, $\gamma-\mathrm{Fe}_{2} \mathrm{O}_{3}$, with a well-defined stoichiometric structure, are synthesized by the borohydride reduction of ferric chloride at an elevated temperature $\left(100{ }^{\circ} \mathrm{C}\right)$ followed by thermal treatment of the reaction product. The binding of the magnetic material with rhodamine B isothiocyanate results in the fluorescent magnetic nanocarrier providing, at the same time, a spacer arm for covalent immobilization of other biosubstances, including enzymes [71]. Water-soluble poly(poly(ethyleneglycol)monomethacrylate)-grafted (P(PEGMA)-grafted) $\mathrm{Fe}_{3} \mathrm{O}_{4}$ nanoparticles synthesized via a solvent-free atom transfer radical polymerization (ATRP) method were conveniently surface-modified with 3-aminopropyltrimethoxysilane as anchor molecules to donate $\mathrm{NH}_{2}$ groups. Fluorescent magnetic NPs were then obtained by covalently bonding FITC to the $\mathrm{NH}_{2}$ groups (Figure 9) [72].

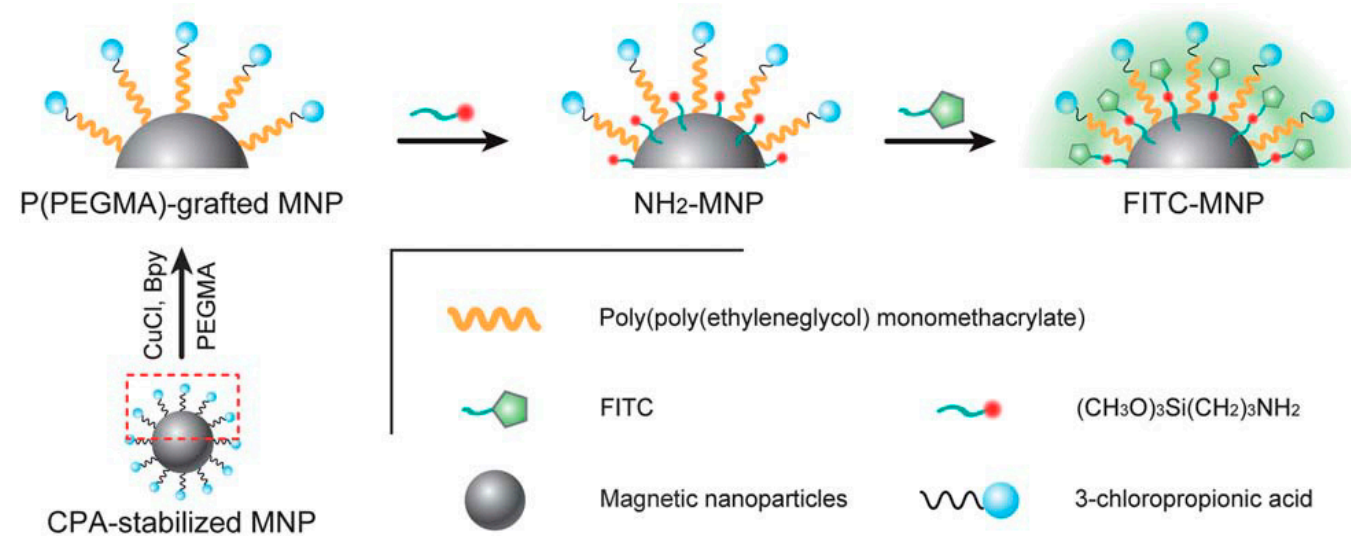

Figure 9. Preparation route of $\mathrm{NH}_{2}$-MNPs and FITC-MNPs from P(PEGMA)-MNPs by post-polymerization modification (MNPs-magnetic nanoparticles). Adapted from ref. [72].

Huand et al. used a second-generation photosensitizer Chlorin e6 (Ce6) that was covalently conjugated to the surface of the magnetic nanoparticles with a silane coupling agent. Ce6 molecules retained their spectroscopic properties and functionalisation to be used in various imaging applications [73]. Wate et al. fabricated a multicomponent nanostructure system that involves the covalent attachment of 3 components; $\mathrm{Fe}_{3} \mathrm{O}_{4}$ (Fe) NPs, PAMAM-G4- $\mathrm{NH}_{2}$ (G4) dendrimer and $\mathrm{Cy} 5(\mathrm{Cy})$ on a graphene oxide (GO) surface to develop a biologically multifunctional system. The resultant GO-G4-Fe-Cy nanosystem exhibits high dispersion in aqueous media, and is magnetically responsive and fluorescent [74]. Yen et al. reported the synthesis of an amphiphilic polymer, poly(isobutylene-alt-maleic anhyride)-functionalized near-infrared IR-820 dye and its conjugates with iron oxide $\left(\mathrm{Fe}_{3} \mathrm{O}_{4}\right)$ magnetic NPs for optical and MRI imaging (Figure 10) [75]. After the absorption of dopamine, human serum albumin (HSA) was attached to the surface of the $\mathrm{CoFe}_{2} \mathrm{O}_{4}$ magnetic NPs through a reversible non-covalent bond between $\mathrm{HSA}$ and $-\mathrm{NH}_{2}$ in dopamine. With the same type of 
interaction, the designed perylenediimide (PDI) based $-\mathrm{NH}_{2}$ rich fluorescent molecule (PDI- $4 \mathrm{NH}_{2}$ ) was decorated onto the HSA-modified $\mathrm{CoFe}_{2} \mathrm{O}_{4}$ nanoparticles (Figure 11) [76].

a)

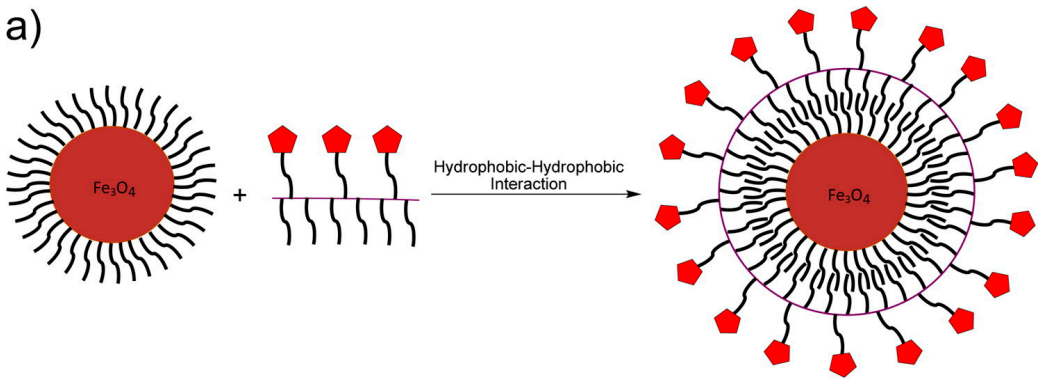

b)

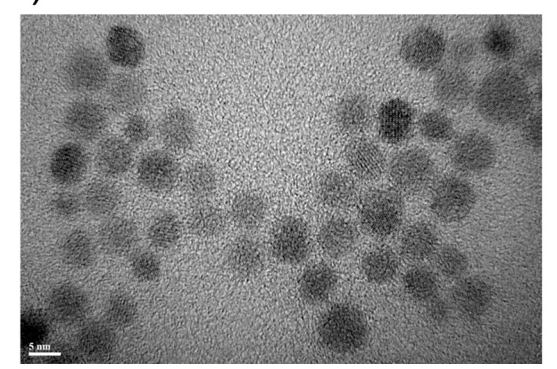

c)

d)

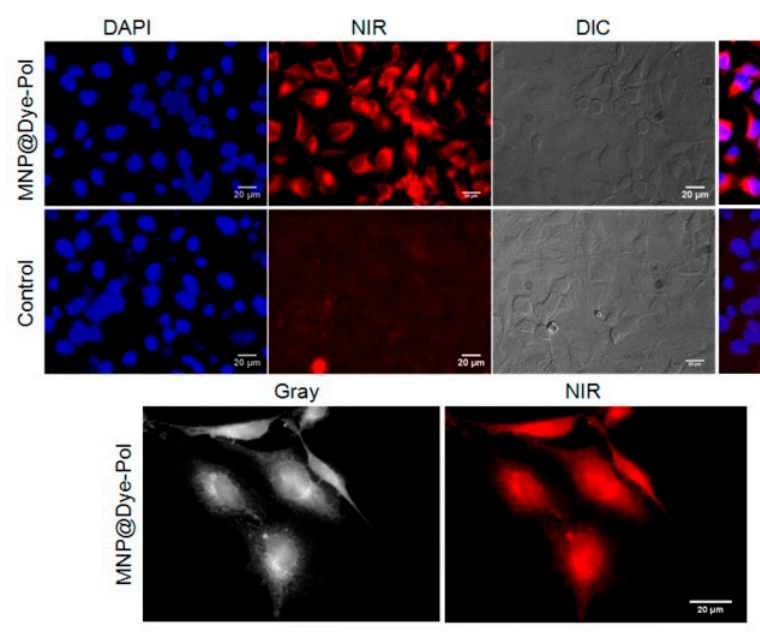

e)

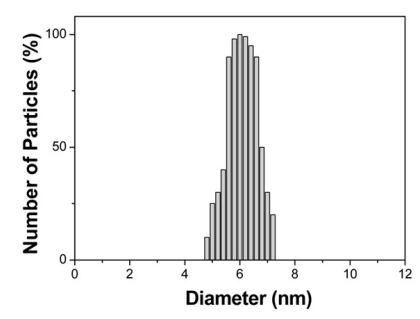

Overlay

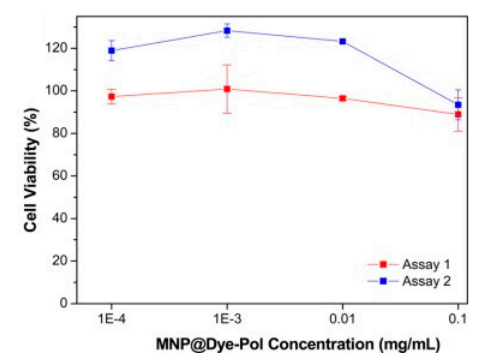

Figure 10. Top: (a) Schematic illustration of Dye-Pol-conjugated $\mathrm{Fe}_{3} \mathrm{O}_{4}$ magnetic nanoparticles (MNPs) through hydrophobic interaction, yielding MNP@Dye-Pol. (b) HRTEM and (c) Size-distribution of MNP@Dye-Pol. (d) Labeling of HeLa cells incubated for $2 \mathrm{~h}$ with $50 \mu \mathrm{L}$ of MNP@Dye-Pol $(1 \mathrm{mg} / \mathrm{mL})$. Blue (DAPI), red (NIR), and DIC channels. (Lower panel) Images at high magnification. Scale bar: $20 \mu \mathrm{m}$. (e) In vitro cell viability of HeLa cells incubated for $24 \mathrm{~h}$ (assay 1 ) and $6 \mathrm{~h}$ (assay 2 ) at $37^{\circ} \mathrm{C}$ with different concentrations of MNP@Dye-Pol. Cell viability assays were carried out using CellTiter-Blue in triplicate. The error bars represent the standard deviations. Adapted from ref. [75]. 


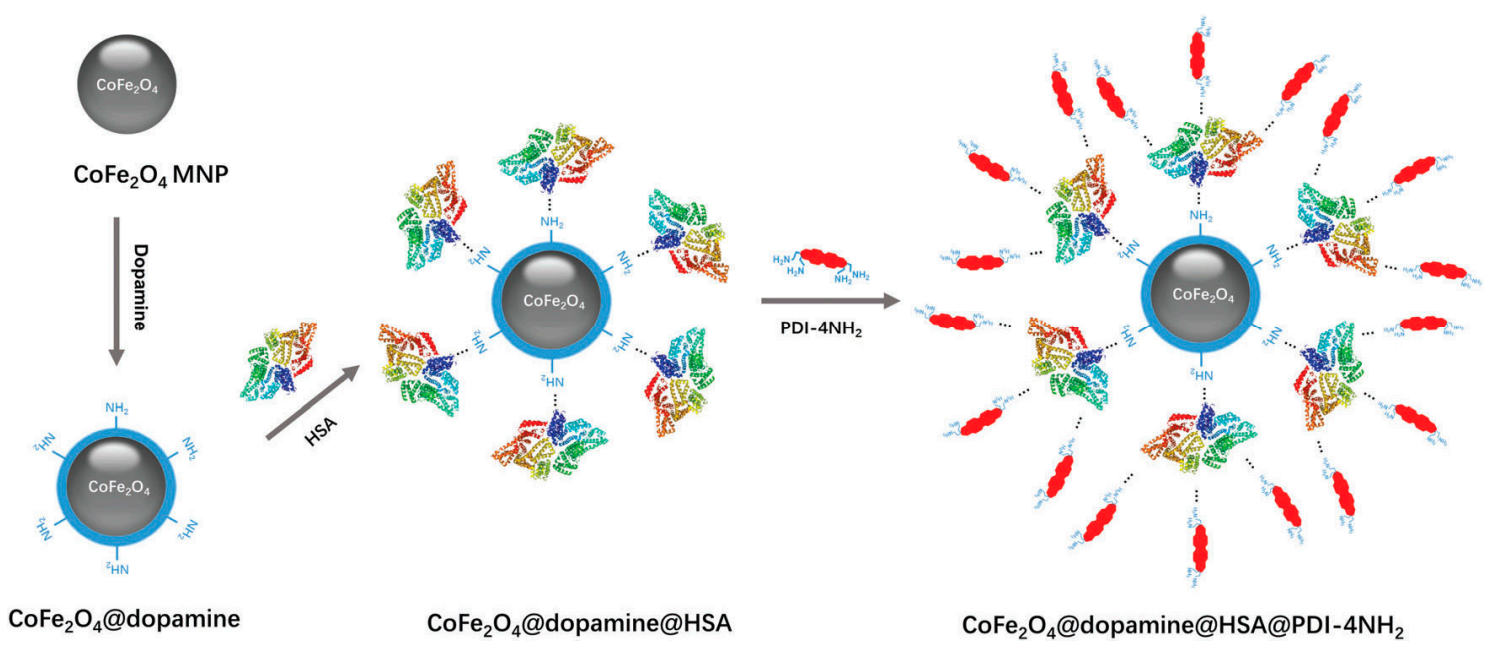

Figure 11. Synthetic procedure for the preparation of fluorescent $\mathrm{CoFe}_{2} \mathrm{O}_{4}$ magnetic nanoparticles. Adapted from ref. [76].

A fluorescent ruthenium ( $\mathrm{Ru}$ ) complex was coupled to magnetic $\mathrm{Fe}_{3} \mathrm{O}_{4}$ nanoparticles (NPs) via 3-(3,4-dihydroxyphenyl) propanoic acid (DHPPA) and O,O'-bis(2-aminopropyl) polypropylene glycol-block-polyethylene glycol-block-polypropylene glycol (PPG-PEG-PPG-diamine) [77]. Water soluble $\mathrm{Fe}_{3} \mathrm{O}_{4}$-DPA-PEG NPs were conjugated with the fluorescent $\mathrm{Eu}$ (III) complex of tris(dibenzoylmethane)5-amino-1,10-phenanthroline (BMAP), giving an $\mathrm{Fe}_{3} \mathrm{O}_{4}$-DPA-PEG-BMAP-Eu NPs conjugate. The conjugate was both colloidally and chemically stable in phosphate buffered solutions and could be used as a probe for magnetic resonance and fluorescent imaging [78].

Novel $\mathrm{Fe}_{3} \mathrm{O}_{4} @ \mathrm{YPO}_{4}$ : $\mathrm{Re}(\mathrm{Re}=\mathrm{Tb}, \mathrm{Eu})$ magnetic-fluorescent hybrid nanospheres are prepared and show a sustained release behaviour for the anticancer drug DOX and successful labelling of human cervical carcinoma Hela cells [79]. In the first step, St and NIPAM polymerize the NaUA on the surface of $\mathrm{Fe}_{3} \mathrm{O}_{4}$ nanoparticles to form $\mathrm{Fe}_{3} \mathrm{O}_{4} /$ poly(St-NIPAM) nanoparticles which act as seeds for the polymerization of $\mathrm{Eu}(\mathrm{AA})_{3}$ Phen, with the remaining St and NIPAM in the second step, forming an outer fluorescent layer [80]. The Poly(MMA-HEMA-Eu(AA) $\left.)_{3} \mathrm{Phen}\right) / \mathrm{Fe}_{3} \mathrm{O}_{4}$ nanospheres exhibit magnetic and fluorescent properties that are favorable for use in drug delivery, magnetic separation and MRI [81].

The microsphere formulations of Chit/TPP $/ \mathrm{Sm} / \mathrm{Fe}_{3} \mathrm{O}_{4} / \mathrm{Rn}$ were also prepared by an ionic gelation technique, where Chito = chitosan, TPP = tripolyphosphate, $\mathrm{Sm}=$ samarium and $\mathrm{Rn}=$ ranitidine. This microsphere formulation was found to exhibit excellent magnetic and fluorescent properties [82].

\section{Applications of Multimodal Fluorescent-Magnetic Nanoparticles}

Fluorescent-magnetic nanoparticles have found many biological applications such as multimodal bioimaging agents, diagnostic tools, drug delivery and hyperthermia/photodynamic therapy systems.

\subsection{Multimodal Bioimaging}

Molecular imaging refers to the study of biological processes at the cellular and/or molecular level. There are different biological imaging techniques such as optical bioluminescence, optical fluorescence, ultrasound imaging, MRI, single-photon-emission computed tomography (SPECT), and positron emission tomography (PET). The important feature in the use of multimodal magnetic nanoparticles is that they can act as probes for imaging applications and also can be loaded with drugs and used as drug carriers for therapeutic applications.

MRI is among one of the main in vivo imaging techniques while fluorescence and confocal microscopies are widely used for in vitro studies, which makes these imaging techniques complementary. 
Therefore, fluorescent-magnetic nanomaterials offer a unique opportunity as dual contrast agents that can be used both in fluorescent microscopy and in MRI-thus opening new prospects in medical diagnostics.

MRI involves the imaging of protons present in the soft tissues in the human body composed of proteins, water and lipids. Proton spins align under the presence of an applied magnetic field, B0. These protons are perturbed from B0 when a transverse radiofrequency pulse is applied. Subsequently, protons return to their original state through a process of relaxation. These processes are known as T1 (longitudinal relaxation) and T2 (transverse relaxation time) and generate a magnetic resonance image. Difference in relaxations is related to the density or the chemical and physical nature of the tissues under study [83]. The acting mechanism of $\mathrm{T} 2$ contrast agents is as follows: both relaxation time, T1 and $\mathrm{T} 2$, can be shortened by the use of a magnetic contrast agent. The coating of the nanoparticles can cause a delay in the shortening of the relaxation time but the distance between the protons and the contrast agent has to be minimized. Generally, T1 uses paramagnetic complexes, such as gadolinium diethylenetriaminepentaacetic acid (Gd-DTPA) as contrast agents [84,85].

Magnetic field gradients arise when T2 is shortened due to the difference in the susceptibility between the magnetic material and the medium around them. This gradient causes the diffusion of the protons that leads to a decrease in the relaxation time of the protons. In this case, superparamagnetic nanoparticles are useful as negative contrast agents (T2) [86].

Optical imaging is a complementary tool to magnetic resonance imaging since it provides a better performance in sensibility and spatial resolution for in vitro imaging. However, tissue penetration is limited to few millimetres, and so MRI provides better in vivo images and also provides excellent deep tissue contrast and spatial resolution.

Fluorescent magnetic nanoparticles can be used as multimodal agents combining contrast agents and magnetic manipulation. Interesting advances have been achieved in recent years in the development of these types of materials. For example, Zhang et al. designed iron oxide nanoparticles of about $10 \mathrm{~nm}$ coated with fluorescent mesoporous silica for neutral progenitor cell MRI. The material demonstrated high magnetic resonance sensitivity and excellent cell labelling efficiency (Figure 12) [87]. Iron oxide nanoparticles were engineered with dopamine to modify the surface of the material that was subsequently encapsulated into human serum albumin matrices. This nanosystem was labelled with ${ }^{64} \mathrm{Cu}$-DOTA and Cy5.5 and tested in a subcutaneous U87MG xenograft mouse model. In vivo positron emission tomography (PET)/NIR/magnetic resonance imaging (MRI) tri-modal imaging, and ex vivo analyses and histological examinations were conducted to investigate the in vivo behavior of the nanostructures [88]. Monodisperse P(PEGMA)-grafted magnetic nanoparticles functionalized with the organic dye FITC showed optical activity and good biocompatibility. MMt assay using 3T3 fibroblast revealed the low cytotoxicity of the composite indicating the potential of the material to be used in bioimaging [72]. In another study, multifunctional core@shell $\left(\mathrm{CoFe}_{2} \mathrm{O}_{4} @ \mathrm{MnFe}_{2} \mathrm{O}_{4}\right)$ nanostructures coated with tetramethylrhodamine-5-carboxamide cadaverine labeled poly(isobutylene-alt-maleic anhydride), PEG and functionalized with folic acid for targeting demonstrated good biocompatibility, high T2 relaxation values, and long-term fluorescence stability. These fluorescent magnetic nanocomposites have been used to effectively enhance the targeted MRI and fluorescent labeling in vitro and in vivo [89]. 
(a)
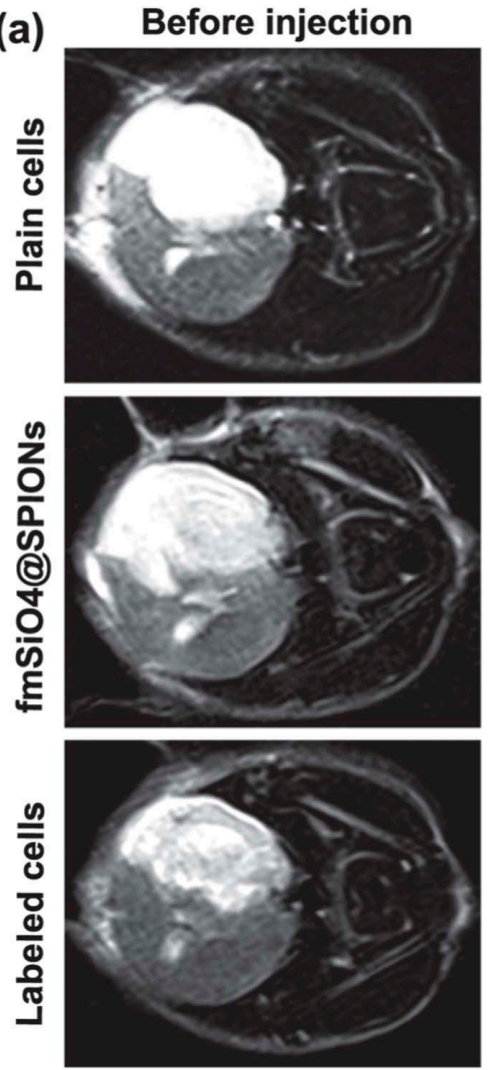

(b)

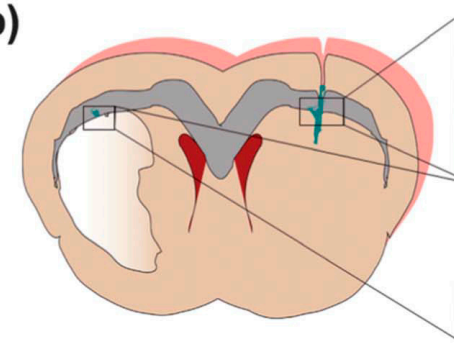

Day 1
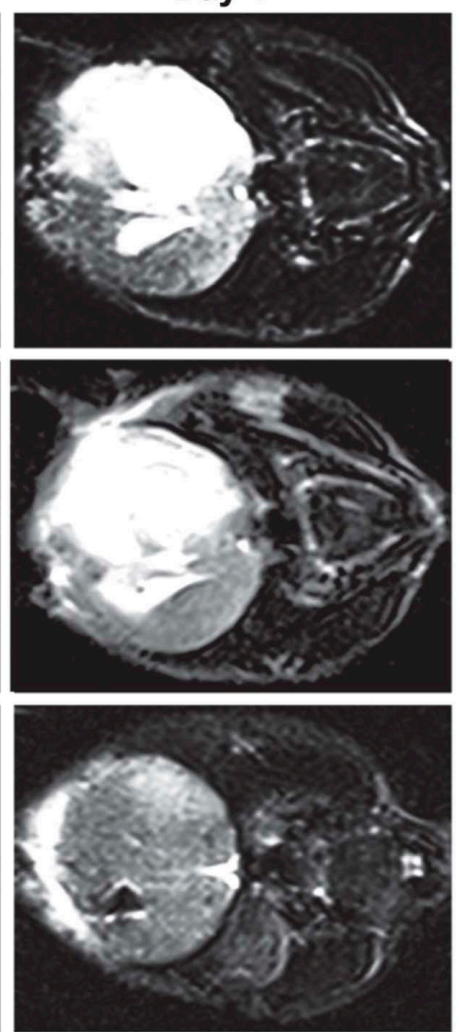

FITC

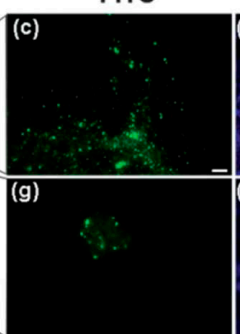

Day 3
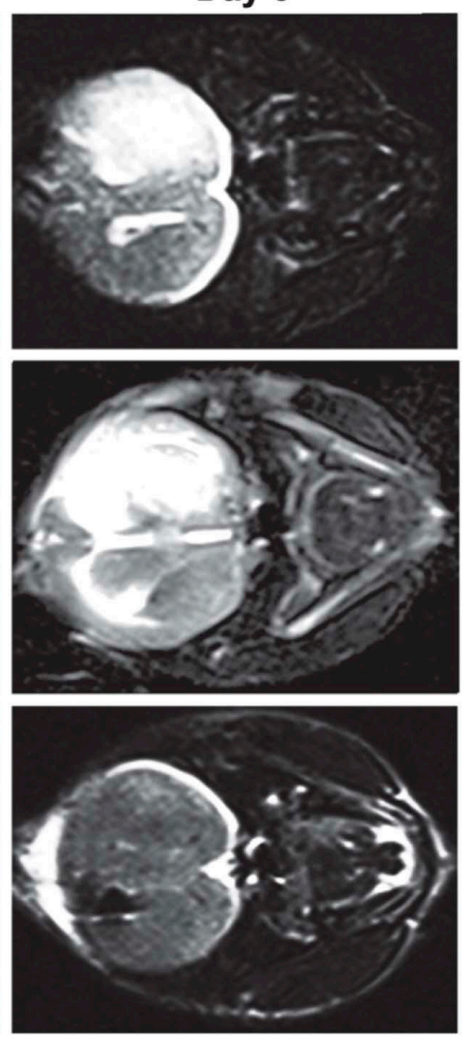

Nestin

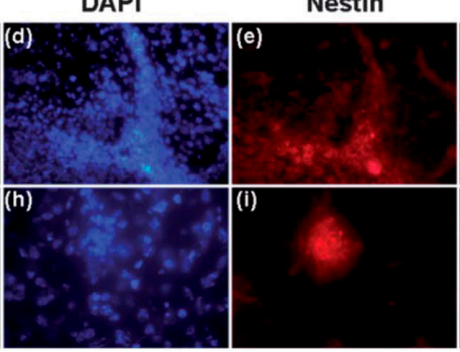

Merge

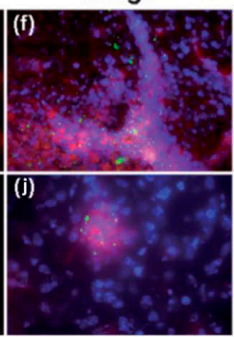

Figure 12. MRI tracking of $\mathrm{fmSiO}_{4} @ S P I O N-l a b e l e d ~ C 17.2$ cells infused intracerebrally, contralateral to the ischemic area and histological studies of MCAO mouse brain. (a) $T_{2}$-weighted magnetic resonance images of MCAO mouse brains after injection with plain cells, $\mathrm{fmSiO}_{4} @ S P I O N s$ or $\mathrm{fmSiO}_{4} @$ SPION-labeled C17.2 cells; (b) Scheme of a brain section indicating the sites of migrated cells; $(\mathbf{c}-\mathbf{j})$ fluorescence images of MCAO mouse brain sections after infusion of $\mathrm{fmSiO}_{4} @ S P I O N-l a b e l e d$ C17.2 cells; ( $\mathbf{c}-\mathbf{f})$ labelled cells confined in the injection site; $(\mathbf{g}-\mathbf{j})$ labelled cells migrating to the ischemic area; $(\mathbf{c}, \mathbf{g})$ fluorescence images of $\mathrm{fmSiO}_{4} @ S P I O N-l a b e l e d ~ C 17.2$ cells; $(\mathbf{d}, \mathbf{h})$ DAPI staining of cell nuclei; $(\mathbf{e}, \mathbf{i})$ nestinimmunostaining of the labelled cells; (f) overlap of $(\mathbf{c}-\mathbf{e})$; (j) overlap of $(\mathbf{g}-\mathbf{i})$. Scale bar: $50 \mu \mathrm{m}$. Adapted from ref. [87].

\subsection{Cancer Therapy}

Back in 1957, Gilchist et al. carried out investigations using magnetic nanoparticles in hyperthermia. The experiment involved heating of tissue samples containing $\gamma-\mathrm{Fe}_{2} \mathrm{O}_{3}$ nanoparticles in a size range of 20-100 $\mathrm{nm}$ and exposed to a 1.2 MHz magnetic field [90]. Magnetic hyperthermia is heating of the nanoparticles previously placed in a targeted tissue by applying an AC magnetic field. Consequently, the heat is applied directly to the diseased tissue surrounding the magnetic material and the cancer is destroyed if the temperature can be held at $42{ }^{\circ} \mathrm{C}$ for $30 \mathrm{~min}$. This technique gives the possibility of treating cancer cells directly by heating while the healthy tissues are kept untouched. The principles of hyperthermia are also based on the fact that cancer cells are more sensitive to the changes in 
temperature than healthy cells. Magnetic nanomaterials are chosen for this technique because they are able to absorb the energy from the AC magnetic field to convert it to heat, and the effect of the resultant heating is higher than for other materials. Another advantage of using magnetic nanoparticles is that they can be targeted to the cancer cells magnetically or using biomarkers to ensure that only the intended target tissue is heated [1]. The main drawbacks of magnetic hyperthermia include the necessity of a high dosage of magnetic nanoparticles in tumor to achieve reasonable hyperthermia effect, the toxicity of nanomaterials used and high costs [91,92].

By contrast, photodynamic therapy involves the administration of a photosensitizing drug followed by the illumination of the target tissue with light corresponding to the absorbance wavelength of the drug, that results in generation of highly reactive singlet oxygen killing cancer cells [93]. This therapy has some advantages including the precise targeting of drugs, low costs, less invasive (compared to surgery) and it can also be repeated many times. However, photodynamic therapy can only be used to treat tissues that could be exposed to light and it is not suitable in the case of cancer that has spread to many places in the body. In addition, photodynamic therapy requires extra precautions as photosensitizing drugs cause high sensitivity of the patient's body to light for some period of time [94].

Overall, magnetic hyperthermia and photodynamic therapy could be complementary methods in the cancer treatment and used together, if appropriate magnetic-photosensitizing nanocomposites are available. It has been previously demonstrated that hyperthermia and photodynamic therapy can be synergistic and there was a clear enhancement of the effects of 5-aminolevulinic acid-mediated photodynamic therapy by concurrent hyperthermia in glioma spheroids [95]. It was also shown that photodynamic therapy effects can be greatly enhanced by thermal modulation that results in an increase of reactive oxygen species in albumin-photosensitizer nanoassemblies [94]. In addition, these therapies can be combined together with MRI and optical imaging enabling the monitoring of the treatment. For example, agents based on magnetic nanoparticles covalently bound to the surface of photosensitizer Chlorine6 showed excellent spectroscopic and functional properties for NIR fluorescent imaging and photodynamic therapy, as well as in drug delivery and MRI due to the presence of the magnetic core nanoparticles [73].

$\mathrm{Xu}$ et al. prepared highly biocompatible luminescent superparamagnetic nanocomposites that consisted of $\mathrm{Fe}_{3} \mathrm{O}_{4} / \mathrm{SiO}_{2}-\mathrm{QDs}$. This material acted as a high-efficiency $\mathrm{RF}$ absorber and showed optical ability for cell labelling, i.e., characteristics that make it an interesting material for use as a hyperthermia agent in pancreatic cancer therapy, among other medical applications [17]. Another example of a fluorescent magnetic nanomaterial the showed interesting properties to be used in hyperthermia in the combination of magnetic nanoparticles and IR-emitting QDs was synthesised by Ortgies et al. The nanocomposite allows monitoring of the distribution of the nanoparticles in vivo, which is important for MRI and optical imaging based tomography and also presents potential for magnetic hyperthermia treatments [56].

In another study, magnetic nanoemulsions loaded with citrate-coated maghemite nanoparticles and chloroaluminumphthalocyanine have been used as agents for in vitro combined magnetic hyperthermia and photodynamic therapy (at $670 \mathrm{~nm}$ wavelength) in the treatment of different cancer cell line models. It was found that the use of magnetic hyperthermia resulted in only $15 \%$ of the cell viability reduction, while the use of only photodynamic therapy treatment yielded a52\% decrease in the cell viability. Most importantly, the total reduction of the cell viability about $70 \%$ was achieved by combining the magnetic hyperthermia and photodynamic therapy treatments [96].

Finally, it was demonstrated recently that multifunctional nanomaterials comprising of magnetic $\mathrm{Fe}_{3} \mathrm{O}_{4}$ nanoparticles and photosensitizer conjugated hyaluronic acid can be used for enhanced tumor diagnosis and therapy. These nanocomposites showed enhanced water solubility, heat and singlet oxygen generation properties. In addition, the combination of magnetic hyperthermia and photodynamic therapy treatment resulted in synergistically enhanced tumor growth inhibition efficacy. 
The multifunctional nanomaterial was used for in vivo detection of tumors implanted in mice using MRI and optical imaging [91].

\subsection{Drug Delivery}

In the last decades, magnetic nanoparticles have become an important advanced tool for applications such as drug delivery. Magnetic nanoparticles can be manipulated with an external magnetic field and driven to the desired target area, i.e., cancerous tissue, where the drug can be released and act directly. This advance in medicine enables the reduction of the drug dosage and potential elimination of side effects [97]. The success of this therapy strongly depends on the selection of the targeting moiety to have specific affinity of binding to the cell surface receptors [98].

The high surface area of the nanoparticles allows for a large amount of drug to be adsorbed. However, magnetic nanoparticles used in drug delivery must be functionalized with groups that can assure their biocompatibility [99].

Fluorescent magnetic nanoparticles provide the possibility of performing integrated functionalities, enabling them to perform both bioimaging and therapy functions. The incorporation of a fluorescent entity allows the tracking of the nanocomposite while different drugs can be released inside the tissue or in the target area under treatment.

For example, Mohapatra et al. developed highly luminescent magnetic hybrid nanoparticles consisting of a magnetic core and mesoporous carbon as an outer layer. The resultant material showed magnetic resonance contrast behavior by affecting the proton relaxation with transverse relaxivity. In vitro cell experiments demonstrated that the material loaded with DOX can be endocyted by tumour cells through passive targeting [36]. Multifunctional fluorescent-magnetic polyethyleneimine functionalized $\mathrm{Fe}_{3} \mathrm{O}_{4}$ with a mesoposous silica shell nanocapsules were prepared for fluorescent tracking and the delivery of RNA. The cavities of the mesoporous silica shell have the ability to carry $\beta$-actin siRNA into Hela cells for simultaneous visualization and magnetically guided gene delivery [40]. Magneto-thermally responsive DOX-encapsulated supramolecular magnetic nanoparticles were prepared by Lee et al. The system was tested for the delivery and release of DOX in an optimized in vivo treatment. This system showed a considerable decrease of the drug dosage compared to existing protocols, which may increase the clinical opportunities for other drugs with good therapeutic efficacy but high toxicity with important side effects [54].

A graphene oxide (GO)-based fluorescent magnetic hybrid was reported by Gao et al. for loading and delivery water-soluble aromatic anti-cancer drugs such as DOX. The maximum loading capacity of DOX to the GO-based magnetic fluorescent hybrids was $91.9 \%$. DOX preferred release from DOX loaded GO-based magnetic fluorescent hybrids under acidic conditions. A HepG2 cell line was used to evaluate the capability of the hybrids with respect todrug delivery and imaging, and their morphology after study indicated the DOX loaded GO-based magnetic fluorescent hybrids displayed an excellent therapeutic effect on the target tumours [30].

\section{Conclusions and Future Outlook}

There has been substantial progress in the development of multifunctional fluorescent-magnetic nanomaterials and their biomedical applications over last 10 years. The development of new synthetic approaches involving silica and various polymer coatings enabled us to address issues related to paramagnetic quenching of fluorophore by magnetic components. The new fluorescent-magnetic nanocomposites have been successfully used for biological imaging, hyperthermia and drug delivery applications. However, one of the major challenges and roadblocks for in vivo applications of multifunctional fluorescent-magnetic nanocomposites is their potential toxicity. Despite very extensive studies of toxicity of many nanomaterials, the results are still inconclusive, and further research on the toxicity and of biocompatibility of fluorescent-magnetic nanocomposites is necessary. Moreover, fluorescent-magnetic nanomaterials are quite attractive objects in terms of their in vitro and in vivo toxicity studies; due to the dual modality, they can be easily monitored by fluorescence microscopy 
in vitro and MRI in vivo, enabling identification and visualization of their bio-distribution. In addition, this research will be necessary for further development of potential drug delivery systems based on fluorescent-magnetic nanostructures.

Fluorescent-magnetic nanocomposites are also very promising candidates for multimodal theranostic materials which could serve as all-in-one contrast agents, photosensitizers for photodynamic therapy and hyperthermia agents at the same time. This important goal can be realised, for example, by combining magnetic nanoparticles and organic dyes which are traditionally used in photodynamic therapy (e.g., porphyrin or phthalocyanine derivatives). In addition fluorescent-magnetic nanocomposites can be easily functionalized with specific biomarkers (e.g., antibodies, receptors, etc.) that would facilitate their targeted delivery to specific sites (e.g., tumors) in the body. This would be of particular importance, as one of the major drawbacks of any chemotherapy is the difficulty in delivering the drug to the biological site of interest. In addition, it is essential to notice that in this case, all processes could be monitored by MRI and fluorescence microscopy techniques, allowing the full control of the medical procedures. However, this area of research is still in the very early stage of development and requires intensive future studies.

Overall, we believe that further development of new magnetic-fluorescent nanomaterials will be very important for advances in modern biology and medicine.

Acknowledgments: This work was supported by the EU-ITN network Mag(net)icFun (PITN-GA-2012-290248) and Irish Research Council (IRC) postgraduate scheme.

Author Contributions: All authors wrote and cross-checked the manuscript together.

Conflicts of Interest: The authors declare no conflict of interest.

\section{References}

1. Hilger, I.; Hergt, R.; Kaiser, W.A. Use of magnetic nanoparticle heating in the treatment of breast cancer. IEE Proc. Nanobiotechnol. 2005, 152, 33-39. [CrossRef] [PubMed]

2. Du, K.; Zhu, Y.H.; Xu, H.B.; Yang, X.L. Multifunctional Magnetic Nanoparticles: Synthesis, Modification and Biomedical Applications. Prog. Chem. 2011, 23, 2287-2298.

3. Huang, S.H.; Juang, R.S. Biochemical and biomedical applications of multifunctional magnetic nanoparticles: A review. J. Nanopart. Res. 2011, 13, 4411-4430. [CrossRef]

4. Schladt, T.D.; Schneider, K.; Schild, H.; Tremel, W. Synthesis and bio-functionalization of magnetic nanoparticles for medical diagnosis and treatment. Dalton Trans. 2011, 40, 6315-6343. [CrossRef] [PubMed]

5. Mahmoudi, M.; Serpooshan, V.; Laurent, S. Engineered nanoparticles for biomolecular imaging. Nanoscale 2011, 3, 3007-3026. [CrossRef] [PubMed]

6. Le Trequesser, Q.; Seznec, H.; Delville, M.H. Functionalized nanomaterials: Their use as contrast agents in bioimaging: Mono- and multimodal approaches. Nanotechnol. Rev. 2013, 2, 125-169. [CrossRef]

7. Yan, K.; Li, P.H.; Zhu, H.E.; Zhou, Y.J.; Ding, J.D.; Shen, J.; Li, Z.; Xu, Z.S.; Chu, P.K. Recent advances in multifunctional magnetic nanoparticles and applications to biomedical diagnosis and treatment. RSC Adv. 2013, 3, 10598-10618. [CrossRef]

8. Padmanabhan, P.; Kumar, A.; Kumar, S.; Chaudhary, R.K.; Gulyas, B. Nanoparticles in practice for molecular-imaging applications: An overview. Acta Biomater. 2016, 41, 1-16. [CrossRef] [PubMed]

9. Cherukula, K.; Lekshmi, K.M.; Uthaman, S.; Cho, K.; Cho, C.S.; Park, I.K. Multifunctional Inorganic Nanoparticles: Recent Progress in Thermal Therapy and Imaging. Nanomaterials 2016, 6, 76. [CrossRef] [PubMed]

10. Jing, L.H.; Ding, K.; Kershaw, S.V.; Kempson, I.M.; Rogach, A.L.; Gao, M.Y. Magnetically Engineered Semiconductor Quantum Dots as Multimodal Imaging Probes. Adv. Mater. 2014, 26, 6367-6386. [CrossRef] [PubMed]

11. Jana, N.R. Design and development of quantum dots and other nanoparticles based cellular imaging probe. Phys. Chem. Chem. Phys. 2011, 13, 385-396. [CrossRef] [PubMed]

12. Corr, S.A.; Rakovich, Y.P.; Gun'ko, Y.K. Multifunctional magnetic-fluorescent nanocomposites for biomedical applications. Nanosc. Res. Lett. 2008, 3, 87-104. [CrossRef] 
13. Koole, R.; Mulder, W.J.M.; van Schooneveld, M.M.; Strijkers, G.J.; Meijerink, A.; Nicolay, K. Magnetic quantum dots for multimodal imaging. Wiley Interdiscip. Rev. Nanomed. Nanobiotechnol. 2009, 1, 475-491. [CrossRef] [PubMed]

14. Gao, J.H.; Gu, H.W.; Xu, B. Multifunctional Magnetic Nanoparticles: Design, Synthesis, and Biomedical Applications. Acc. Chem. Res. 2009, 42, 1097-1107. [CrossRef] [PubMed]

15. Shi, D.L.; Sadat, M.E.; Dunn, A.W.; Mast, D.B. Photo-fluorescent and magnetic properties of iron oxide nanoparticles for biomedical applications. Nanoscale 2015, 7, 8209-8232. [CrossRef] [PubMed]

16. Acharya, A. Luminescent Magnetic Quantum Dots for In Vitro/In Vivo Imaging and Applications in Therapeutics. J. Nanosci. Nanotechnol. 2013, 13, 3753-3768. [CrossRef] [PubMed]

17. Xu, Y.; Karmakar, A.; Wang, D.; Mahmood, M.W.; Watanabe, F.; Zhang, Y.; Fejleh, A.; Fejleh, P.; Li, Z.; Kannarpady, G. Multifunctional $\mathrm{Fe}_{3} \mathrm{O}_{4}$ cored magnetic-quantum dot fluorescent nanocomposites for RF nanohyperthermia of cancer cells. J. Phys. Chem. C 2010, 114, 5020-5026. [CrossRef]

18. Lim, E.-K.; Yang, J.; Dinney, C.P.N.; Suh, J.-S.; Huh, Y.-M.; Haam, S. Self-assembled fluorescent magnetic nanoprobes for multimode-biomedical imaging. Biomaterials 2010, 31, 9310-9319. [CrossRef] [PubMed]

19. Chekina, N.; Horak, D.; Jendelova, P.; Trchova, M.; Benes, M.J.; Hruby, M.; Herynek, V.; Turnovcova, K.; Sykova, E. Fluorescent magnetic nanoparticles for biomedical applications. J. Mater. Chem. 2011, 21, 7630-7639. [CrossRef]

20. Wang, F.; Chen, X.; Zhao, Z.; Tang, S.; Huang, X.; Lin, C.; Cai, C.; Zheng, N. Synthesis of magnetic, fluorescent and mesoporous core-shell-structured nanoparticles for imaging, targeting and photodynamic therapy. J. Mater. Chem. 2011, 21, 11244-11252. [CrossRef]

21. Jiaqi, W.; Xiangxi, M.; Enzhong, L.; Kezheng, C. Incorporation of magnetite nanoparticle clusters in fluorescent silica nanoparticles for high-performance brain tumor delineation. Nanotechnology 2010, 21, 235104. [CrossRef]

22. Badruddoza, A.Z.M.; Rahman, M.T.; Ghosh, S.; Hossain, M.Z.; Shi, J.; Hidajat, K.; Uddin, M.S. $\beta$-Cyclodextrin conjugated magnetic, fluorescent silica core-shell nanoparticles for biomedical applications. Carbohydr. Polym. 2013, 95, 449-457. [CrossRef] [PubMed]

23. Torkpur-Biglarianzadeh, M.; Salami-Kalajahi, M. Multilayer fluorescent magnetic nanoparticles with dual thermoresponsive and $\mathrm{pH}$-sensitive polymeric nanolayers as anti-cancer drug carriers. RSC Adv. 2015, 5, 29653-29662. [CrossRef]

24. Li, L.; Liu, C.; Zhang, L.; Wang, T.; Yu, H.; Wang, C.; Su, Z. Multifunctional magnetic-fluorescent eccentric-(concentric- $\left.\mathrm{Fe}_{3} \mathrm{O}_{4} @ \mathrm{SiO}_{2}\right) @$ polyacrylic acid core-shell nanocomposites for cell imaging and pH-responsive drug delivery. Nanoscale 2013, 5, 2249-2253. [CrossRef] [PubMed]

25. Ebrahiminezhad, A.; Ghasemi, Y.; Rasoul-Amini, S.; Barar, J.; Davaran, S. Preparation of novel magnetic fluorescent nanoparticles using amino acids. Colloids Surf. B Biointerfaces 2013, 102, 534-539. [CrossRef] [PubMed]

26. Cho, Y.-S.; Yoon, T.-J.; Jang, E.-S.; Hong, K.S.; Lee, S.Y.; Kim, O.R.; Park, C.; Kim, Y.-J.; Yi, G.-C.; Chang, K. Cetuximab-conjugated magneto-fluorescent silica nanoparticles for in vivo colon cancer targeting and imaging. Cancer Lett. 2010, 299, 63-71. [CrossRef] [PubMed]

27. Lu, Y.; He, B.; Shen, J.; Li, J.; Yang, W.; Yin, M. Multifunctional magnetic and fluorescent core-shell nanoparticles for bioimaging. Nanoscale 2015, 7, 1606-1609. [CrossRef] [PubMed]

28. Sun, L.; Zang, Y.; Sun, M.; Wang, H.; Zhu, X.; Xu, S.; Yang, Q.; Li, Y.; Shan, Y. Synthesis of magnetic and fluorescent multifunctional hollow silica nanocomposites for live cell imaging. J. Colloid Interface Sci. 2010, 350, 90-98. [CrossRef] [PubMed]

29. Song, E.; Han, W.; Li, J.; Jiang, Y.; Cheng, D.; Song, Y.; Zhang, P.; Tan, W. Magnetic-encoded fluorescent multifunctional nanospheres for simultaneous multicomponent analysis. Anal. Chem. 2014, 86, 9434-9442. [CrossRef] [PubMed]

30. Gao, Y.; Zou, X.; Zhao, J.X.; Li, Y.; Su, X. Graphene oxide-based magnetic fluorescent hybrids for drug delivery and cellular imaging. Colloids Surf. B Biointerfaces 2013, 112, 128-133. [CrossRef] [PubMed]

31. Wang, K.; Ruan, J.; Qian, Q.; Song, H.; Bao, C.; Zhang, X.; Kong, Y.; Zhang, C.; Hu, G.; Ni, J. BRCAA1 monoclonal antibody conjugated fluorescent magnetic nanoparticles for in vivo targeted magnetofluorescent imaging of gastric cancer. J. Nanobiotechnol. 2011, 9, 23. [CrossRef] [PubMed]

32. Koc, K.; Karakus, B.; Rajar, K.; Alveroglu, E. Synthesis and characterization of $\mathrm{ZnS@Fe} 3 \mathrm{O}_{4}$ fluorescent-magnetic bifunctional nanospheres. Superlattices Microstruct. 2017, 110, 198-204. [CrossRef] 
33. Yin, N.; Wu, P.; Liang, G.; Cheng, W. A multifunctional mesoporous $\mathrm{Fe}_{3} \mathrm{O}_{4} / \mathrm{SiO}_{2} / \mathrm{CdTe}$ magnetic-fluorescent composite nanoprobe. Appl. Phys. A 2016, 122, 243. [CrossRef]

34. Gui, R.; Wang, Y.; Sun, J. Encapsulating magnetic and fluorescent mesoporous silica into thermosensitive chitosan microspheres for cell imaging and controlled drug release in vitro. Colloids Surf. B Biointerfaces 2014, 113, 1-9. [CrossRef] [PubMed]

35. Borgohain, C.; Senapati, K.K.; Mishra, D.; Sarma, K.C.; Phukan, P. A new $\mathrm{CoFe}_{2} \mathrm{O}_{4}-\mathrm{Cr}_{2} \mathrm{O}_{3}-\mathrm{SiO}_{2}$ fluorescent magnetic nanocomposite. Nanoscale 2010, 2, 2250-2256. [CrossRef] [PubMed]

36. Mohapatra, S.; Rout, S.R.; Das, R.K.; Nayak, S.; Ghosh, S.K. Highly hydrophilic luminescent magnetic mesoporous carbon nanospheres for controlled release of anticancer drug and multimodal imaging. Langmuir 2016, 32, 1611-1620. [CrossRef] [PubMed]

37. Wang, X.; He, F.; Tang, F.; Ma, N.; Li, L. Preparation of hybrid fluorescent-magnetic nanoparticles for application to cellular imaging by self-assembly. Colloids Surf. A Physicochem. Eng. Asp. 2011, 392, 103-109. [CrossRef]

38. Pfaff, A.; Schallon, A.; Ruhland, T.M.; Majewski, A.P.; Schmalz, H.; Freitag, R.; Müller, A.H. Magnetic and fluorescent glycopolymer hybrid nanoparticles for intranuclear optical imaging. Biomacromolecules 2011, 12, 3805-3811. [CrossRef] [PubMed]

39. Chen, D.; Jiang, M.; Li, N.; Gu, H.; Xu, Q.; Ge, J.; Xia, X.; Lu, J. Modification of magnetic silica/iron oxide nanocomposites with fluorescent polymethacrylic acid for cancer targeting and drug delivery. J. Mater. Chem. 2010, 20, 6422-6429. [CrossRef]

40. Zhang, L.; Wang, T.; Li, L.; Wang, C.; Su, Z.; Li, J. Multifunctional fluorescent-magnetic polyethyleneimine functionalized $\mathrm{Fe}_{3} \mathrm{O}_{4}$-mesoporous silica yolk-shell nanocapsules for siRNA delivery. Chem. Commun. 2012, 48, 8706-8708. [CrossRef] [PubMed]

41. Mi, C.; Zhang, J.; Gao, H.; Wu, X.; Wang, M.; Wu, Y.; Di, Y.; Xu, Z.; Mao, C.; Xu, S. Multifunctional nanocomposites of superparamagnetic $\left(\mathrm{Fe}_{3} \mathrm{O}_{4}\right)$ and NIR-responsive rare earth-doped up-conversion fluorescent $\left(\mathrm{NaYF}_{4}: \mathrm{Yb}, \mathrm{Er}\right)$ nanoparticles and their applications in biolabeling and fluorescent imaging of cancer cells. Nanoscale 2010, 2, 1141-1148. [CrossRef] [PubMed]

42. Gai, S.; Yang, P.; Li, C.; Wang, W.; Dai, Y.; Niu, N.; Lin, J. Synthesis of Magnetic, Up-Conversion Luminescent, and Mesoporous Core-Shell-Structured Nanocomposites as Drug Carriers. Adv. Funct. Mater. 2010, 20, 1166-1172. [CrossRef]

43. Lehmann, A.D.; Parak, W.J.; Zhang, F.; Ali, Z.; Röcker, C.; Nienhaus, G.U.; Gehr, P.; Rothen-Rutishauser, B. Fluorescent-Magnetic Hybrid Nanoparticles Induce a Dose-Dependent Increase in Proinflammatory Response in Lung Cells in vitro Correlated with Intracellular Localization. Small 2010, 6, 753-762. [CrossRef] [PubMed]

44. Xu, H.; Cheng, L.; Wang, C.; Ma, X.; Li, Y.; Liu, Z. Polymer encapsulated upconversion nanoparticle/iron oxide nanocomposites for multimodal imaging and magnetic targeted drug delivery. Biomaterials 2011, 32, 9364-9373. [CrossRef] [PubMed]

45. Howes, P.; Green, M.; Bowers, A.; Parker, D.; Varma, G.; Kallumadil, M.; Hughes, M.; Warley, A.; Brain, A.; Botnar, R. Magnetic Conjugated Polymer Nanoparticles as Bimodal Imaging Agents. J. Am. Chem. Soc. 2010, 132, 9833-9842. [CrossRef] [PubMed]

46. He, X.; Wu, X.; Cai, X.; Lin, S.; Xie, M.; Zhu, X.; Yan, D. Functionalization of Magnetic Nanoparticles with Dendritic-Linear-Brush-Like Triblock Copolymers and Their Drug Release Properties. Langmuir 2012, 28, 11929-11938. [CrossRef] [PubMed]

47. Sato, K.; Abe, E.; Takahashi, M.; Anzai, J.-I. Loading and release of fluorescent dye from layer-by-layer film-coated magnetic particles in response to hydrogen peroxide. J. Colloid Interface Sci. 2014, 432, 92-97. [CrossRef] [PubMed]

48. Li, K.; Ding, D.; Huo, D.; Pu, K.Y.; Thao, N.N.P.; Hu, Y.; Li, Z.; Liu, B. Conjugated Polymer Based Nanoparticles as Dual-Modal Probes for Targeted In Vivo Fluorescence and Magnetic Resonance Imaging. Adv. Funct. Mater. 2012, 22, 3107-3115. [CrossRef]

49. Wang, L.; Neoh, K.-G.; Kang, E.-T.; Shuter, B.; Wang, S.-C. Biodegradable magnetic-fluorescent magnetite/poly(DL-lactic acid-co- $\alpha, \beta$-malic acid) composite nanoparticles for stem cell labeling. Biomaterials 2010, 31, 3502-3511. [CrossRef] [PubMed] 
50. Wang, S.; Yang, W.; Du, H.; Guo, F.; Wang, H.; Chang, J.; Gong, X.; Zhang, B. Multifunctional reduction-responsive SPIO\&DOX-loaded PEGylated polymeric lipid vesicles for magnetic resonance imaging-guided drug delivery. Nanotechnology 2016, 27, 165101. [CrossRef] [PubMed]

51. Zhu, H.; Shang, Y.; Wang, W.; Zhou, Y.; Li, P.; Yan, K.; Wu, S.; Yeung, K.W.; Xu, Z.; Xu, H. Fluorescent Magnetic $\mathrm{Fe}_{3} \mathrm{O}_{4} /$ Rare Earth Colloidal Nanoparticles for Dual-Modality Imaging. Small 2013, 9, 2991-3000. [CrossRef] [PubMed]

52. Yan, K.; Li, H.; Li, P.; Zhu, H.; Shen, J.; Yi, C.; Wu, S.; Yeung, K.W.K.; Xu, Z.; Xu, H.; et al. Self-assembled magnetic fluorescent polymeric micelles for magnetic resonance and optical imaging. Biomaterials 2014, 35, 344-355. [CrossRef] [PubMed]

53. Perillo, E.; Hervé-Aubert, K.; Allard-Vannier, E.; Falanga, A.; Galdiero, S.; Chourpa, I. Synthesis and in vitro evaluation of fluorescent and magnetic nanoparticles functionalized with a cell penetrating peptide for cancer theranosis. J. Colloid Interface Sci. 2017, 499, 209-217. [CrossRef] [PubMed]

54. Lee, J.H.; Chen, K.J.; Noh, S.H.; Garcia, M.A.; Wang, H.; Lin, W.Y.; Jeong, H.; Kong, B.J.; Stout, D.B.; Cheon, J. On-demand drug release system for in vivo cancer treatment through self-assembled magnetic nanoparticles. Angew. Chem. 2013, 125, 4480-4484. [CrossRef]

55. Hu, J.; Xie, M.; Wen, C.-Y.; Zhang, Z.-L.; Xie, H.-Y.; Liu, A.-A.; Chen, Y.-Y.; Zhou, S.-M.; Pang, D.-W. A multicomponent recognition and separation system established via fluorescent, magnetic, dualencoded multifunctional bioprobes. Biomaterials 2011, 32, 1177-1184. [CrossRef] [PubMed]

56. Ortgies, D.H.; de la Cueva, L.; del Rosal, B.; Sanz-Rodríguez, F.; Fernández, N.; Iglesias-de la Cruz, M.C.; Salas, G.; Cabrera, D.; Teran, F.J.; Jaque, D.; et al. In Vivo Deep Tissue Fluorescence and Magnetic Imaging Employing Hybrid Nanostructures. ACS Appl. Mater. Interfaces 2016, 8, 1406-1414. [CrossRef] [PubMed]

57. Lou, L.; Yu, K.; Zhang, Z.; Li, B.; Zhu, J.; Wang, Y.; Huang, R.; Zhu, Z. Functionalized magnetic-fluorescent hybrid nanoparticles for cell labelling. Nanoscale 2011, 3, 2315-2323. [CrossRef] [PubMed]

58. Koktysh, D.; Bright, V.; Pham, W. Fluorescent magnetic hybrid nanoprobe for multimodal bioimaging. Nanotechnology 2011, 22, 275606. [CrossRef] [PubMed]

59. Xie, M.; Hu, J.; Wen, C.-Y.; Zhang, Z.-L.; Xie, H.-Y.; Pang, D.-W. Fluorescent-magnetic dual-encoded nanospheres: A promising tool for fast-simultaneous-addressable high-throughput analysis. Nanotechnology 2011, 23, 035602. [CrossRef] [PubMed]

60. Vargas, J.M.; McBride, A.A.; Plumley, J.B.; Fichou, Y.; Memon, T.A.; Shah, V.; Cook, N.C.; Akins, B.A.;

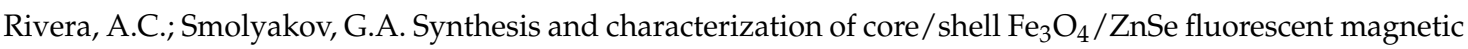
nanoparticles. J. Appl. Phys. 2011, 109, 07B536. [CrossRef] [PubMed]

61. Ruan, G.; Vieira, G.; Henighan, T.; Chen, A.; Thakur, D.; Sooryakumar, R.; Winter, J.O. Simultaneous Magnetic Manipulation and Fluorescent Tracking of Multiple Individual Hybrid Nanostructures. Nano Lett. 2010, 10, 2220-2224. [CrossRef] [PubMed]

62. Cho, H.-S.; Dong, Z.; Pauletti, G.M.; Zhang, J.; Xu, H.; Gu, H.; Wang, L.; Ewing, R.C.; Huth, C.; Wang, F.; et al. Fluorescent, Superparamagnetic Nanospheres for Drug Storage, Targeting, and Imaging: A Multifunctional Nanocarrier System for Cancer Diagnosis and Treatment. ACS Nano 2010, 4, 5398-5404. [CrossRef] [PubMed]

63. Chen, B.; Zhang, H.; Zhai, C.; Du, N.; Sun, C.; Xue, J.; Yang, D.; Huang, H.; Zhang, B.; Xie, Q.; et al. Carbon nanotube-based magnetic-fluorescent nanohybrids as highly efficient contrast agents for multimodal cellular imaging. J. Mater. Chem. 2010, 20, 9895-9902. [CrossRef]

64. Liu, L.; Xiao, L.; Zhu, H.-Y. Preparation and characterization of CS-Fe $\mathrm{O}_{4} @ \mathrm{ZnS}: \mathrm{Mn}$ magnetic-fluorescent nanoparticles in aqueous media. Chem. Phys. Lett. 2012, 539, 112-117. [CrossRef]

65. Walia, S.; Sharma, S.; Markand Kulurkar, P.; Patial, V.; Acharya, A. A bimodal molecular imaging probe based on chitosan encapsulated magneto-fluorescent nanocomposite offers biocompatibility, visualization of specific cancer cells in vitro and lung tissues in vivo. Int. J. Pharm. 2016, 498, 110-118. [CrossRef] [PubMed]

66. Li, P.; Song, Y.; Liu, C.; Li, X.; Zhou, G.; Fan, Y. Magnetic and fluorescent bifunctional chitosan microspheres embedding with fluorescent-labeling drug as a drug delivery system. Mater. Lett. 2014, 114, 132-135. [CrossRef]

67. Jha, D.K.; Saikia, K.; Chakrabarti, S.; Bhattacharya, K.; Varadarajan, K.S.; Patel, A.B.; Goyary, D.; Chattopadhyay, P.; Deb, P. Direct one-pot synthesis of glutathione capped hydrophilic FePt-CdS nanoprobe for efficient bimodal imaging application. Mater. Sci. Eng. C 2017, 72, 415-424. [CrossRef] [PubMed]

68. Ding, Y.; Yin, H.; Shen, S.; Sun, K.; Liu, F. Chitosan-based magnetic/fluorescent nanocomposites for cell labelling and controlled drug release. New J. Chem. 2017, 41, 1736-1743. [CrossRef] 
69. McCarthy, J.E.; Prina-Mello, A.; Rakovich, T.; Volkov, Y.; Gun'ko, Y.K. Fabrication and characterization of multimodal magnetic-Fluorescent polystyrene nanowires as selective cell imaging probes. J. Mater. Chem. 2011, 21, 14219-14225. [CrossRef]

70. Hwang, D.W.; Song, I.C.; Lee, D.S.; Kim, S. Smart magnetic fluorescent nanoparticle imaging probes to monitor microRNAs. Small 2010, 6, 81-88. [CrossRef] [PubMed]

71. Magro, M.; Sinigaglia, G.; Nodari, L.; Tucek, J.; Polakova, K.; Marusak, Z.; Cardillo, S.; Salviulo, G.; Russo, U.; Stevanato, R.; et al. Charge binding of rhodamine derivative to $\mathrm{OH}-$ stabilized nanomaghemite: Universal nanocarrier for construction of magnetofluorescent biosensors. Acta Biomater. 2012, 8, 2068-2076. [CrossRef] [PubMed]

72. Lu, X.; Jiang, R.; Fan, Q.; Zhang, L.; Zhang, H.; Yang, M.; Ma, Y.; Wang, L.; Huang, W. Fluorescent-magnetic poly(poly(ethyleneglycol)monomethacrylate)-grafted $\mathrm{Fe}_{3} \mathrm{O}_{4}$ nanoparticles from post-atom-transfer-radical-polymerization modification: Synthesis, characterization, cellular uptake and imaging. J. Mater. Chem. 2012, 22, 6965-6973. [CrossRef]

73. Huang, P.; Li, Z.; Lin, J.; Yang, D.; Gao, G.; Xu, C.; Bao, L.; Zhang, C.; Wang, K.; Song, H.; et al. Photosensitizer-conjugated magnetic nanoparticles for in vivo simultaneous magnetofluorescent imaging and targeting therapy. Biomaterials 2011, 32, 3447-3458. [CrossRef] [PubMed]

74. Wate, P.S.; Banerjee, S.S.; Jalota-Badhwar, A.; Mascarenhas, R.R.; Zope, K.R.; Khandare, J.; Misra, R.D.K. Cellular imaging using biocompatible dendrimer-functionalized graphene oxide-based fluorescent probe anchored with magnetic nanoparticles. Nanotechnology 2012, 23, 415101. [CrossRef] [PubMed]

75. Yen, S.K.; Jańczewski, D.; Lakshmi, J.L.; Dolmanan, S.B.; Tripathy, S.; Ho, V.H.B.; Vijayaragavan, V.; Hariharan, A.; Padmanabhan, P.; Bhakoo, K.K.; et al. Design and Synthesis of Polymer-Functionalized NIR Fluorescent Dyes-Magnetic Nanoparticles for Bioimaging. ACS Nano 2013, 7, 6796-6805. [CrossRef] [PubMed]

76. Yao, Q.; Zheng, Y.; Cheng, W.; Chen, M.; Shen, J.; Yin, M. Difunctional fluorescent HSA modified $\mathrm{CoFe}_{2} \mathrm{O}_{4}$ magnetic nanoparticles for cell imaging. J. Mater. Chem. B 2016, 4, 6344-6349. [CrossRef]

77. Xi, P.; Cheng, K.; Sun, X.; Zeng, Z.; Sun, S. Fluorescent magnetic nanoparticles based on a ruthenium complex and $\mathrm{Fe}_{3} \mathrm{O}_{4}$. J. Mater. Chem. 2011, 21, 11464-11467. [CrossRef]

78. Xi, P.; Cheng, K.; Sun, X.; Zeng, Z.; Sun, S. Magnetic $\mathrm{Fe}_{3} \mathrm{O}_{4}$ nanoparticles coupled with a fluorescent Eu complex for dual imaging applications. Chem. Commun. 2012, 48, 2952-2954. [CrossRef] [PubMed]

79. Wang, W.; Zou, M.; Chen, K. Novel $\mathrm{Fe}_{3} \mathrm{O}_{4} @ \mathrm{YPO}_{4}$ : $\mathrm{Re}(\mathrm{Re}=\mathrm{Tb}, \mathrm{Eu})$ multifunctional magnetic-fluorescent hybrid spheres for biomedical applications. Chem. Commun. 2010, 46, 5100-5102. [CrossRef] [PubMed]

80. Zhu, H.; Tao, J.; Wang, W.; Zhou, Y.; Li, P.; Li, Z.; Yan, K.; Wu, S.; Yeung, K.W.K.; Xu, Z.; et al. Magnetic, fluorescent, and thermo-responsive $\mathrm{Fe}_{3} \mathrm{O}_{4} /$ rare earth incorporated poly(St-NIPAM) core-shell colloidal nanoparticles in multimodal optical/magnetic resonance imaging probes. Biomaterials 2013, 34, 2296-2306. [CrossRef] [PubMed]

81. Hu, C.; Xia, T.; Gong, Y.; Wang, X.; Liu, R.-Q.; Zhang, Q.-Y.; Yi, C.-F.; Xu, Z.-S.; Guo, D.-Z. Emulsifier-free emulsion polymerized poly (MMA-HEMA-Eu (AA) 3Phen) $/ \mathrm{Fe}_{3} \mathrm{O}_{4}$ magnetic fluorescent bifunctional nanospheres for magnetic resonance and optical imaging. Chin. J. Polym. Sci. 2016, 34, 135-146. [CrossRef]

82. Kusrini, E.; Prassanti, R.; Nurjaya, D.M.; Gunawan, C. Multifunctional Microsphere Formulation of Fluorescent Magnetic Properties for Drug Delivery System; AIP Conference Proceedings; AIP Publishing: Melville, NY, USA, 2017.

83. Carretta, P.; Lascialfari, A. NMR-MRI, $\mu S R$ and Mössbauer Spectroscopies in Molecular Magnets; Springer-Verlag Mailand: Milan, Italy, 2007.

84. Catherine, C.B.; Adam, S.G.C. Functionalisation of magnetic nanoparticles for applications in biomedicine. J. Phys. D Appl. Phys. 2003, 36, R198. [CrossRef]

85. Mi, P.; Kokuryo, D.; Cabral, H.; Kumagai, M.; Nomoto, T.; Aoki, I.; Terada, Y.; Kishimura, A.; Nishiyama, N.; Kataoka, K. Hydrothermally synthesized PEGylated calcium phosphate nanoparticles incorporating Gd-DTPA for contrast enhanced MRI diagnosis of solid tumors. J. Control. Release 2014, 174, 63-71. [CrossRef] [PubMed]

86. Casula, M.F.; Floris, P.; Innocenti, C.; Lascialfari, A.; Marinone, M.; Corti, M.; Sperling, R.A.; Parak, W.J.; Sangregorio, C. Magnetic resonance imaging contrast agents based on iron oxide superparamagnetic ferrofluids. Chem. Mater. 2010, 22, 1739-1748. [CrossRef] 
87. Zhang, L.; Wang, Y.; Tang, Y.; Jiao, Z.; Xie, C.; Zhang, H.; Gu, P.; Wei, X.; Yang, G.-Y.; Gu, H.; et al. High MRI performance fluorescent mesoporous silica-coated magnetic nanoparticles for tracking neural progenitor cells in an ischemic mouse model. Nanoscale 2013, 5, 4506-4516. [CrossRef] [PubMed]

88. Xie, J.; Chen, K.; Huang, J.; Lee, S.; Wang, J.; Gao, J.; Li, X.; Chen, X. PET/NIRF/MRI triple functional iron oxide nanoparticles. Biomaterials 2010, 31, 3016-3022. [CrossRef] [PubMed]

89. Zhang, Q.; Yin, T.; Gao, G.; Shapter, J.G.; Lai, W.E.; Huang, P.; Qi, W.; Song, J.; Cui, D.X. Multifunctional Core@Shell Magnetic Nanoprobes for Enhancing Targeted Magnetic Resonance Imaging and Fluorescent Labeling in Vitro and in Vivo. ACS Appl. Mater. Interfaces 2017, 9, 17777-17785. [CrossRef] [PubMed]

90. Gilchrist, R.; Medal, R.; Shorey, W.D.; Hanselman, R.C.; Parrott, J.C.; Taylor, C.B. Selective inductive heating of lymph nodes. Ann. Surg. 1957, 146, 596-606. [CrossRef] [PubMed]

91. Kim, K.S.; Kim, J.; Lee, J.Y.; Matsuda, S.; Hideshima, S.; Mori, Y.; Osaka, T.; Na, K. Stimuli-responsive magnetic nanoparticles for tumor-targeted bimodal imaging and photodynamic/hyperthermia combination therapy. Nanoscale 2016, 8, 11625-11634. [CrossRef] [PubMed]

92. Chatterjee, D.K.; Diagaradjane, P.; Krishnan, S. Nanoparticle-mediated hyperthermia in cancer therapy. Ther. Deliv. 2011, 2, 1001-1014. [CrossRef] [PubMed]

93. Brodin, N.P.; Guha, C.; Tome, W.A. Photodynamic Therapy and Its Role in Combined Modality Anticancer Treatment. Technol. Cancer Res. Treat. 2015, 14, 355-368. [CrossRef] [PubMed]

94. Hu, D.H.; Sheng, Z.H.; Gao, G.H.; Siu, F.M.; Liu, C.B.; Wan, Q.; Gong, P.; Zheng, H.R.; Ma, Y.F.; Cai, L.T. Activatable albumin-photosensitizer nanoassemblies for triple-modal imaging and thermal-modulated photodynamic therapy of cancer. Biomaterials 2016, 93, 10-19. [CrossRef] [PubMed]

95. Hirschberg, H.; Sun, C.H.; Tromberg, B.J.; Yeh, A.T.; Madsen, S.J. Enhanced cytotoxic effects of 5 -aminolevulinic acid-mediated photodynamic therapy by concurrent hyperthermia in glioma spheroids. J. Neuro-Oncol. 2004, 70, 289-299. [CrossRef]

96. De Paula, L.B.; Primo, F.L.; Pinto, M.R.; Morais, P.C.; Tedesco, A.C. Evaluation of a chloroaluminium phthalocyanine-loaded magnetic nanoemulsion as a drug delivery device to treat glioblastoma using hyperthermia and photodynamic therapy. RSC Adv. 2017, 7, 9115-9122. [CrossRef]

97. Mura, S.; Nicolas, J.; Couvreur, P. Stimuli-responsive nanocarriers for drug delivery. Nat. Mater. 2013, 12, 991-1003. [CrossRef] [PubMed]

98. Thorpe, P.E. Vascular Targeting Agents as Cancer Therapeutics. Am. Assoc. Cancer Res. 2004, 10, 415-427. [CrossRef]

99. Knezevic, N.Z.; Lin, V.S.Y. A magnetic mesoporous silica nanoparticle-based drug delivery system for photosensitive cooperative treatment of cancer with a mesopore-capping agent and mesopore-loaded drug. Nanoscale 2013, 5, 1544-1551. [CrossRef] [PubMed]

(C) 2018 by the authors. Licensee MDPI, Basel, Switzerland. This article is an open access article distributed under the terms and conditions of the Creative Commons Attribution (CC BY) license (http://creativecommons.org/licenses/by/4.0/). 